\title{
E1 Puxilí de los Yngas, el ayllu de la nobleza incaica que cuidó de los restos mortales de Atahuallpa Ticci Cápac ${ }^{1}$
}

\author{
Tamara Estupiñán Viteri* \\ Si saben que los cuerpos de los Ingas muertos tenían servicio situado \\ de indios, chácaras, ganados para su servicio y comida... \\ Virrey Francisco de Toledo, 1571
}

Recibido el 14 de noviembre de 2017; aceptado el 11 de enero de 2018

\begin{abstract}
This article discusses the only Inca noble ayllu founded in the Audience of Quito, on the royal estate of Atahuallpa Ticci Cápac, the last Inca emperor of Tahuantinsuyo (the Inca Empire). These lands were inherited by his eldest son, Francisco Topatauchi, the auqui (noble gentleman). The property was located at Cuturiví and Isinchi in the village of Pujilí, $25 \mathrm{~km}$ in a straight line from the Quilotoa volcano lagoon, which, in turn, is $21 \mathrm{~km}$ from the Inca archaeological ruins of Malqui-Machay that were discovered in 2004 and 2010. According to hypotheses based on ethnohistorical evidence, Malqui-Machay may be the

1 La versión original de este artículo fue leída como ponencia, bajo el título "El Puxilí de los Yngas, el único ayllu de la nobleza incaica en la Audiencia de Quito", en el Encuentro Internacional Arqueología y Etnohistoria en los Andes y Tierras Bajas. Dilemas y Miradas complementarias, Cochabamba, Bolivia, 27 de agosto de 2015. En el presente artículo, el texto ha sido revisado, ampliado y actualizado, gracias a los valiosos y acertados comentarios de los doctores Mónica Barnes, César Itier, George Lomné, Bernard Boriello y del arquitecto Leonardo Miño.

Prohibida la reproducción parcial o total del texto, figuras, cuadros y fotografías sin autorización expresa de la autora.

* Investigadora independiente, correo electrónico: tamaraestupinan@hotmail.com
\end{abstract}


emblematic site where the Quito Inca resistance against the Spanish conquerors brought Atahuallpa's mortal remains.

Key words: Atahuallpa Ticci Cápac, Pujili, Cuturiví, Isinchi, Quilotoa, MalquiMachay, ayllu, huauqui, huanca, huaca.

\section{RESUMEN}

En este artículo se discute acerca del único ayllu que la nobleza incaica fundó en la Audiencia de Quito, en las tierras privadas de Atahuallpa Ticci Cápac, el último emperador Inca del Tahuantinsuyo. Estas tierras fueron heredadas por su hijo mayor, Francisco Topatauchi, el auqui (hombre noble). La propiedad estaba ubicada en Cuturiví e Isinchi en el pueblo de Pujilí y está localizada a $25 \mathrm{~km}$ en línea recta de la laguna volcán Quilotoa, que a su vez está a $21 \mathrm{~km}$ de las ruinas arqueológicas incas de Malqui-Machay, descubiertas en los años 2004 y 2010 y que según la hipótesis etnohistórica, habría sido el sitio emblemático al que los incas de la resistencia quiteña contra los conquistadores españoles, llevaron los restos mortales de Atahuallpa.

Palabras clave: Atahuallpa Ticci Cápac, Pujilí, Cuturivi, Isinchi, Quilotoa, MalquiMachay, ayllu, huauqui, huanca, huaca.

\section{PujILÍ: Un MOSAICO ÉTNICO COLONIAL EN EL CORREGIMIENTO DE LATACUNGA}

W ste artículo se relaciona con el único $a y l l u^{2}$ que la nobleza incaica fundó En la Audiencia de Quito, y cuyos miembros, conjuntamente con la élite indígena local, se asentaron durante el período colonial en el corregimiento de Latacunga, actual provincia de Cotopaxi en Ecuador, específicamente en el pueblo nuevo de indios que fundaron los españoles en el siglo XVI en el sitio de Pujilí, emplazado a 2.961 metros de altitud, y que en los documentos de archivo se menciona como el "Puxilí de los Yngas".

2 Esta afirmación tiene como respaldo una base de datos de más de 18.000 registros de fuentes primarias, provenientes básicamente de los libros de protocolos notariales de los archivos de Quito, Latacunga y Salcedo, a lo cual se ha incorporado un fichaje sistemático de los cronistas de Indias y la literatura producida en los siglos XVI y XVII, así como la producción historiográfica más representativa sobre la irrupción del imperio de los incas en el Ecuador aborigen y un complicado trabajo de campo. En este artículo se presenta un avance importante de los resultados finales que serán publicados próximamente en mi libro intitulado Atahuallpa Ticci Cápac, el último Inga hijo del Dios Sol. 
El Pujilí de los ingas fue un reducido mosaico étnico que sobrevivió a la conquista española; entre sus integrantes estaba el hijo más importante que Atahuallpa Ticci Cápac tuvo en Quito, bautizado por los españoles como Francisco Topatauchi, el auqui, ${ }^{3}$ además de otros miembros de la nobleza incaica que descendían de Huayna Cápac Ynga, así como varios ayllus de distinta nacionalidad.

William H. Isbell (1997), en un acertado análisis epistemológico acerca del ayllu, reevalúa desde la historiografía el sentido de esta institución y propone una nueva lectura acerca del pasado andino, para lo cual confronta dos visiones teóricas de la Antropología que abordan el proceso del cambio cultural: por un lado está la hipótesis antigua sobre el ayllu, propuesta desde el evolucionismo procesual y, por otro, aquella generada recientemente por la historia contingente post-procesual. Isbell, en su discusión privilegia el registro arqueológico de los monumentos mortuorios tipo sepulcro abierto, para determinar el origen, la historia y la naturaleza del ayllu, con lo cual establece las limitaciones, inconsistencias e insuficiencias del conocimiento científico sobre esta institución.

En mi opinión, y al margen de las diferencias conceptuales que caracterizan a cada visión teórica, hay un punto de consenso y es que para legitimar la fundación de un ayllu, sea de origen inca o pre-inca, se requiere necesariamente del cuerpo o la momia del ancestro progenitor, en otras palabras, es el cadáver del fundador épico lo que permite la creación de un grupo humano identificado con el idioma del parentesco:

[... ayllu is best understood as a group of people who shared a resource attributed to a founder or ancestor and whose members could therefore be ranked in accord with the idiom of kinship when the founder was employed as a common ancestor. Four elements were essential: Three of these were a social group, a communal resource, and ranking according to kinship idiom. The fourth element held the other three together: a founder or ancestor (Isbell 1997:98-99).

En este estudio de caso, los documentos de archivo confirman la presencia de un grupo exclusivo de la nobleza incaica en un territorio que habría pertenecido a Atahuallpa y su parentela más íntima, no obstante que su cadáver

Según González Holguín (2007 [1608]:46, 228), auqui significa noble, o principal hidalgo y Tupa "Dize cosa Real que toca al Rey". El extirpador de idolatrías, Cristóbal de Albornoz (1967 [c. 1570-1575]:17), proporciona un significado diferente para el mismo vocablo, según su criterio, los incas en los territorios conquistados surtieron a sus habitantes de "[...] unas guaquillas de piedras de diferenciados colores que les llamó auqui, que los traían con sus personas en las chuspas, como los cristianos tienen figuras de santos a quienes reverencian. Servían de paramentos y promesas que hazían en los auquis de tratar verdad en las juntas que hazían para todo género de gobierno". Para Garcilaso de la Vega (1943b [1609]:290), auqui quiere decir infante, de hecho Murúa [Morúa] (2004 [1590]:21 vuelta) lo dibujo como tal, véase el retrato de Ynga Roca Ynga. 
nunca ha sido encontrado, los incas que fundaron este ayllu no podían haberlo constituido sin sus restos mortales, pues como argumenta Isbell (1997:101), el ayllu es inseparable del cuerpo del fundador, ya que su momia era el foco de la organización del grupo identificado por el lenguaje del parentesco y, además, el principal objeto de veneración religiosa de los miembros de esa comunidad, para obtener prosperidad y abundancia.

La nobleza incaica que se asentó en Pujilí, fundó el ayllu ${ }^{4}$ de los ingas e indios chinchaysuyo. El ayllu, a su vez, dio origen al cacicazgo ${ }^{5}$ del mismo nombre y en un solo documento de archivo es referido como ciuitan [civitas] Yupangui Suyo. ${ }^{6}$ Se trata de un linaje de ocho generaciones - excluyendo a

$4 \quad$ Es preciso señalar que en las fuentes primarias utilizadas en este artículo no hay el uso de la palabra quechua panaca para referirse al grupo de la nobleza incaica quiteña que se asentó en Pujilí y que fundó el mencionado ayllu. De otra parte, en la actualidad hay un debate historiográfico sobre la etimología de la voz panaca y su consecuente asociación con la estructura de la nobleza incaica cusqueña integrada por los descendientes de cada gobernante incaico, véase los interesantes cuestionamientos realizados por Francisco Hernández Astete (2015:91-152) y César Itier (2011).

$5 \quad$ Según Itier (2010:191) el vocablo ayllu fue generalmente traducido en las fuentes antiguas como facción o parcialidad o parentela y en el período colonial, la palabra fue reemplazada por el término cacicazgo que deriva de la voz caribeña cacique. En criterio de Garrett (2005:34-36), la institución del cacicazgo fue utilizada por la Corona española para referirse al territorio que gobernaba el cacique o señor étnico del ayllu, cuyo rol principal durante el período colonial fue la recolección de los tributos de una o varias comunidades. El cacique, como jefe étnico de su comunidad, tenía tierras propias e indios para su servicio; fungía, además, como un operador de justicia local y actuaba como interlocutor para la evangelización católica y la enseñanza de vivir en "policía". El cacique también tenía privilegios importantes, como estar exento del pago de tributos o de la mita - trabajo obligatorio- y muchos de ellos llegaron a tener poder político y fortunas propias considerables. Como se puede observar, Garrett define al cacicazgo en términos económicos, sin contemplar los elementos sugeridos por Isbell.

6 El documento más antiguo que se ha registrado sobre el ayllu y/o cacicazgo de los ingas e indios chinchaysuyo data de 1614; véase: Archivo Nacional de Historia, Quito, Indígenas: "Petición de amparo a favor de Sebastián Malqui y otros indios de la parcialidad de los ingas contra Mencia Inga", caja 16, expediente 9, en adelante Libra 1 MFN 2056. En cambio, el documento que más nos acerca al tiempo presente corresponde al año 1819; véase: Archivo Nacional de Historia, Quito, Cacicazgos: "Autos de Antonio Salazar Cordones Betanzos Inga, sobre el cacicazgo de los indios Ingas Chinchasuyos, en el pueblo de Pujilí", caja 9, expediente 14, en adelante Libra 1 MFN 1055. La mención de civitas Yupangui Suyo corresponde al año 1640 y se encuentra como lindero en un litigio de tierras protagonizado por los descendientes del cacique de Latacunga, don Sancho Hacho de Velasco; véase: Archivo Nacional de Historia, Quito, Cacicazgos: "Demanda de María Gregoria Márquez Narváez Sancho Hacho contra María Punina", caja 7, expediente 1, en adelante Libra 1 MFN 0290. Una traducción literal del quechua al castellano de Yupangui Suyo sería parcialidad Yupangui (González Holguín 2007 [1608]:220), empero la asociación en un documento jurídico del grupo de la nobleza incaica con la palabra latina civitas como una expresión espacial urbana que integra a una comunidad de indios organizada de forma cristiana para vivir en "policía", tiene otra connotación. Sobre este tema véase el sugestivo análisis sobre los dominios reales de Topa Ynga Yupangui en Chinchero (Perú), recientemente publicado 
Topa Ynga Yupangue y a su hijo Huayna Cápac Ynga - que se reprodujo durante más de dos siglos (Figura 1) y cuyas prácticas, relacionadas con el culto que los incas tenían hacia sus ancestros progenitores o fundadores de linaje, se rememoran como alegorías encriptadas hasta el día de hoy, pese a que la institución —el cacicazgo - se extinguió con la Ley de División Territorial, decretada por el libertador Simón Bolívar en 1824.

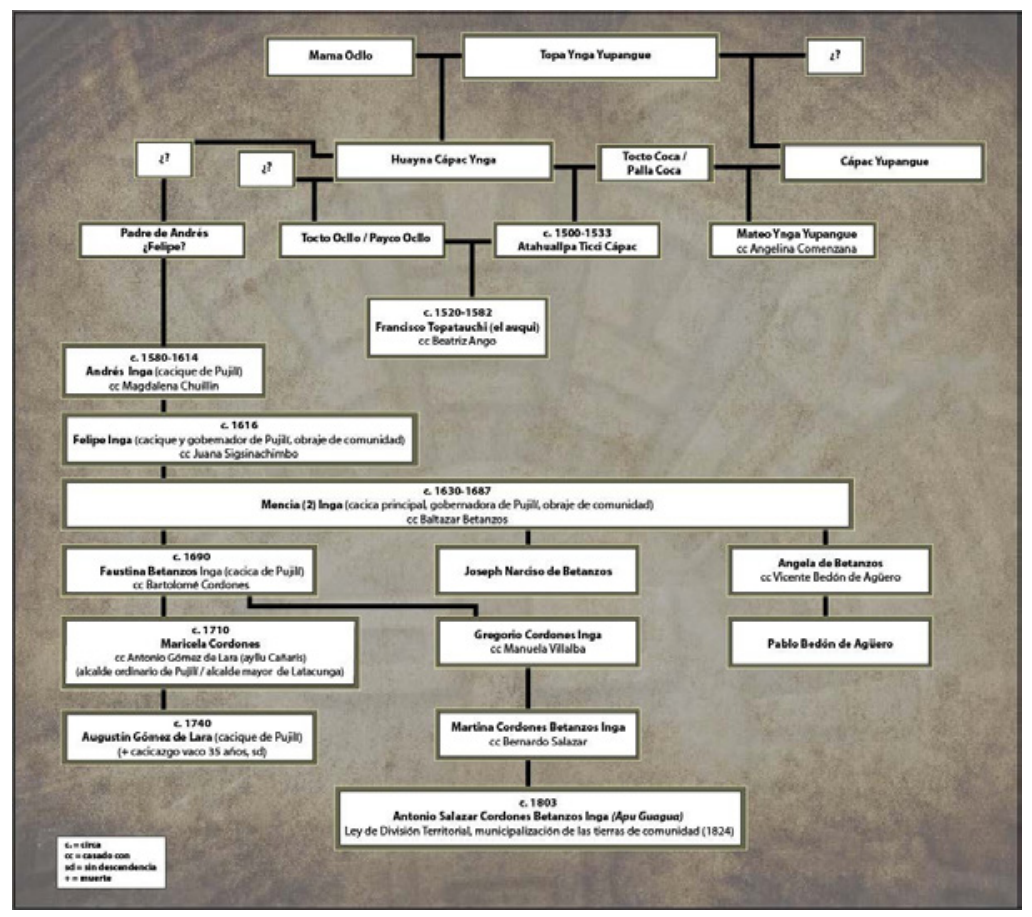

Figura 1. El ayllu de los ingas e indios chinchaysuyo en el pueblo de Pujilí del corregimiento de Latacunga. ${ }^{7}$

por Stella Nair $(2015: 178-179,183,192)$.

7 La genealogía de Atahuallpa y de don Mateo Ynga Yupangue ha sido elaborada con base en las siguientes fuentes primarias y secundarias: Archivo General de Indias, Lima 472, expedientes de Joan de Bustamante Carlos Ynga, sobre la sucesión en el Estado de Oropesa y otros (1563-1748), expediente No. 1, "Mateo Inca Yupanqui solicita que se le confirme el alguacilazgo mayor de Quito, 1563", folios 2-20 v., en adelante Libra 1 MFN 9248; y expediente No. 3, “Alonso Inca Atahuallpa (1586-1587), solicita una merced para volver a la provincia de Quito y un repartimiento de 20.000 pesos", folios 35-93 v., en adelante Libra 1 MFN 9249; Betanzos (1987 [1551-57]:131-132, 193-194); Sarmiento de Gamboa (1942 [1572]:166-167). Para la genealogía de Andrés Inga y sus descendientes se ha utilizado las siguientes fuentes primarias: Libra 1 MFN 1055; Archivos Cotopaxi (Latacunga-Salcedo), "Títulos de las haciendas del General don Antonio Sánchez de Orellana en el Asiento de Latacunga", en adelante Libra 1 MFN 9229; Archivo Nacional de Historia, Quito, Indígenas: 
Según el testamento de Francisco Topatauchi (1582), a quien en ausencia de Atahuallpa le hubiera correspondido recibir la mascapaych $a,{ }^{8}$ tenía nueve propiedades privadas para su sustento, a más de su servidumbre personal. De los bienes patrimoniales que Francisco Topatauchi heredó de su padre, el predio más importante — desde el punto de vista simbólico- estaba ubicado al suroeste del actual pueblo de Pujilí, en el sitio llamado Cuturiví. La propiedad de Cuturiví está rodeada por pequeños cerros y en esa época estaba delimitada por el río de Patoa al norte y el río de Isinchi al sur; ambos afluentes se abren hacia el este, pero no se tiene certeza de dónde estaba el límite de la pertenencia en este punto cardinal. También la demarcación del flanco occidental es incierta, sin embargo, conforme a la "vista de ojos", mencionada en los registros documentales, tenía una máxima abertura hacia el oeste y podía haber llegado hasta la laguna volcán Quilotoa formando un callejón de distintos pisos ecológicos en donde se establecieron varias comunidades indígenas que todavía se consideran "hijos de los ingas". ${ }^{9}$ Estos "hijos de los ingas", aún custodian cerca de su laguna la "cueva del inga" y "loma inga" y son de los pocos grupos étnicos en Ecuador que todavía conservan como lengua materna, el quichua, una variante regional del quechua.

Este grupo étnico que se escondió de los conquistadores españoles, posiblemente fue el que vio el capitán Andrés Contero en 1569, cuando desde Guayaquil, siguiendo el curso del río Babahoyo (Figura 2), entró al corregimiento de Latacunga, ya que en un relato se menciona que él tuvo noticia

\footnotetext{
"Autos de Agustín Gómez de Lara, sobre el cacicazgo de la parcialidad de los indios ingas y chinchasuyos", caja 57, expediente 8, Libra 1 MFN 9196. En el año de 1557, Diego Ylaquita, uno de los hijos de Atahuallpa que se radicó en el Cusco, exhibió una probanza en la que se presentó como testigo a fray Domingo, provincial de la Orden de Santo Domingo, quien declaró que en el monasterio de San Francisco de Quito vivía un hermano de Atahuallpa, llamado don Felipe (Oberem 1976:15); es plausible que este Felipe —contemporáneo de Atahuallpa - sea el padre de don Andrés y que formaba parte, además, del grupo de ingas que se recogió en la laguna del Quilotoa (Carranza 1965 [1569]:88).

$8 \quad$ La mazcca paycha era la borla o insignia real, o corona del rey (González Holguín 2007 [1608]:164). Sobre la sucesión dinástica después de la ejecución de Atahuallpa, según Sancho de la Hoz (1968:294-295, 322), testigo presencial de los acontecimientos en Cajamarca, Francisco Pizarro en reemplazo del monarca, coronó como nuevo señor de la tierra a un hermano menor, llamado también Atabalipa, quien de forma misteriosa murió al poco tiempo. Los conquistadores españoles imputaron a Calicuchima ser el autor de este "crimen", porque se empecinó en que el sucesor debía ser un hijo de Atahuallpa que estaba en Quito, mas no sus hermanos, con lo cual la tierra sería gobernada por los incas quiteños y no por los naturales del Cusco. Pizarro engañó a Calicuchima y antes de tomar posesión del Cusco lo ejecutó, posteriormente proclamó como nuevo inca a Mango Inga, hijo de Huayna Cápac Inca y hermano menor de Atahuallpa.

9 Según conversación personal con Celso Fiallos, trabajo de campo expedición No. 18, 13- 15 de agosto de 2012.
} 
de "[...] la laguna [Quilotoa] donde dicen que están recogidos ciertos Ingas que bajaron de Quito cuando entraron los españoles en la tierra" (Carranza 1965 [1569]:88).

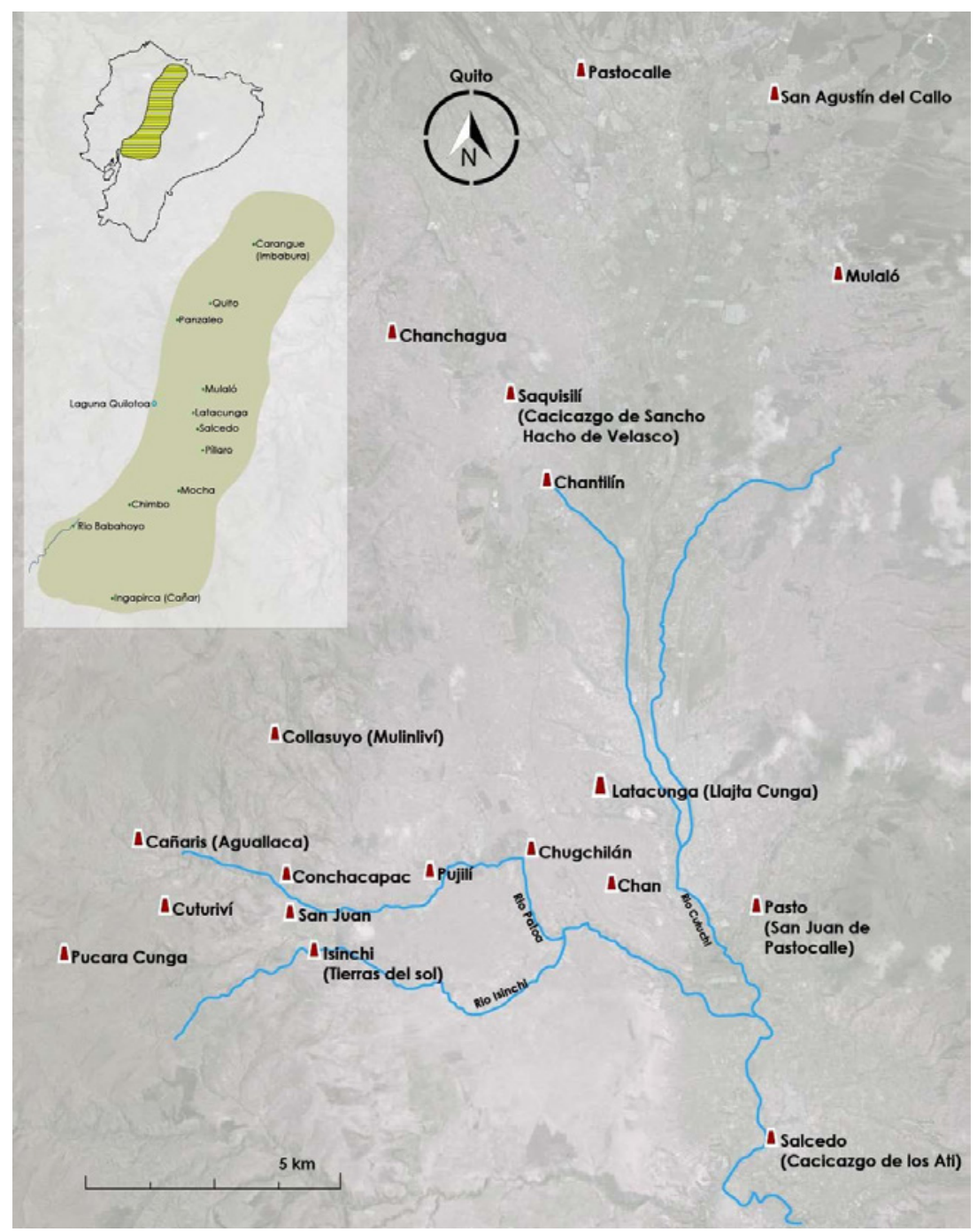

Figura 2. Mosaico étnico del Pujilí de los ingas. 


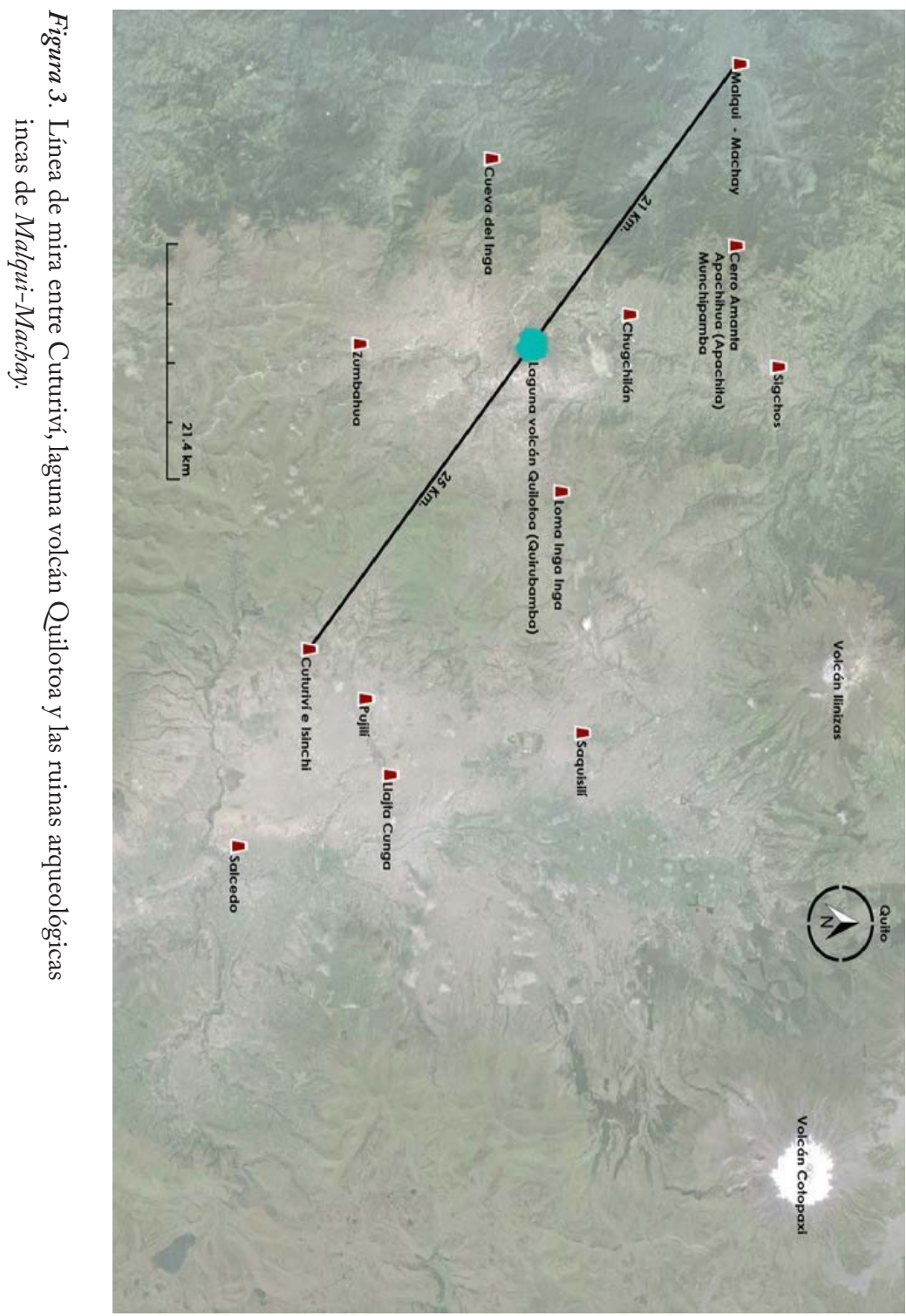

Efectivamente, las tierras de Cuturiví como un solo cuerpo se extendían hasta el volcán de Zumbahua o la laguna hundida en Quirubamba. Actualmente, Zumbahua es un pueblo contiguo a la laguna volcán Quilotoa (Figura 3) y 
podría ser que el topónimo Quilotoa sea una deformación del vocablo quechua Quirubamba, en razón de que aparece de forma tardía en los documentos de $\operatorname{archivo.~}^{10}$

Por su magnificencia paisajística, la laguna volcán Quilotoa es considerada como una huaca ${ }^{11}$ entre los moradores de Zumbahua y de la zona, alrededor de ella hay mitos y leyendas que se refieren a la energía vital que emana y es objeto de una ritualidad en la que se mezclan prácticas del culto cristiano con elementos animistas de la cosmología indígena de origen quechua o inca. ${ }^{12}$

La laguna volcán Quilotoa constituye un punto geográfico intermedio entre Cuturiví y las ruinas arqueológicas incas de Malqui y Machay, ubicadas a 1.020 metros de altitud en la ceja de montaña de Chugchilán, al suroeste de Sigchos, las que fueron descubiertas por mi persona en los años 2004 y 2010, respectivamente. De acuerdo con mi hipótesis, Malqui-Machay habría sido el sitio emblemático al que los incas de la resistencia quiteña contra los conquistadores españoles, comandados por Rumiñahui y Zopozo Pangue, el gobernador inca de Quito, llevaron los restos mortales o el bulto curado de Atahuallpa, después de que fue ejecutado en Cajamarca, el 26 de julio de $1533 . .^{13}$

Como se puede advertir, la selección del sitio de la hacienda privada de Atahuallpa en Cuturiví siguió el modelo cusqueño, al estar ubicada entre los ríos de Patoa e Isinchi con aberturas hacia el este y el oeste, se buscaba un asoleamiento máximo y es factible que las "tierras del Sol" también estuvieran

10 Véase Libra 1 MFN 9229. Consúltese también Libra 1 MFN 2056. El cronista Cieza de León (1996b [1553]:15), en la narración sobre el mito de origen de los incas relacionado con la cueva de Pacaritambo, menciona a la población de Tambo Quiro y explica que traducido al castellano significa dientes de aposento o de palacio. Según Taylor (2008:20) quero o quiru significa vaso de madera. De acuerdo con Blas Valera, pampa es plaza, pero los españoles pronuncian de forma errada como bamba (Loayza 1945:146-147). A finales del siglo XVIII, Coleti (1771:102), ya registró el nombre de la laguna como Quirotoa, que en mi opinión devino en Quilotoa.

11 Según Itier (2010:119-121), las wakas [huaca o guaca], contrariamente a los ancestros fundadores de un ayllu que eran todos hombres, podían ser masculinas o femeninas y eran elementos del paisaje adorados por los incas, sean montañas, lagos, piedras u otras formas naturales que comunicaban su fuerza generatriz en los hombres que ocupaban su territorio y fecundizaban sus campos. Las wakas también eran objeto de ofrendas análogas a aquellas de los ancestros fundadores del ayllu.

12 Sobre las tradiciones, mitos y leyendas de la laguna volcán Quilotoa, véase: Bonaldi (2010).

13 Los vestigios arqueológicos más imponentes están ubicados en Machay, pero hasta la presente fecha no han sido objeto de una investigación arqueológica científica que corrobore, matice o refute la hipótesis formulada desde la etnohistoria, simplemente se han efectuado prospecciones superficiales y trabajos parciales de restauración del complejo arqueológico. En virtud de este lamentable vacío, los esfuerzos por recobrar la historia perdida del destino final del cuerpo y el huauqui de Atahuallpa, así como la fundación del ayllu de la nobleza incaica que cuidó de sus restos mortales, se circunscribe a la evidencia que proporciona la etnohistoria. 
adscritas en el mismo paraje como se discutirá más adelante, en tanto que las tierras de las distintas comunidades gobernadas por el Estado inca se prolongaban hacia el oeste hasta la laguna volcán Quilotoa a pocos kilómetros de Malqui-Machay. ${ }^{14} \mathrm{Si}$ se traza una línea recta entre estos puntos, resulta que la laguna volcán Quilotoa dista a $25 \mathrm{~km}$ de Cuturiví y a $21 \mathrm{~km}$ de las ruinas arqueológicas incas de Malqui-Machay, de tal forma que los sitios "tierras privadas de Atahuallpa Ticci Cápac" y su "morada final” estaban anclados por la huaca laguna volcán Quilotoa (Figura 3).

Haciendo frontera con Cuturiví, los descendientes de Huayna Cápac Ynga también tenían tierras y a diferencia de Francisco Topatauchi, ${ }^{15}$ sí residían en el lugar, de hecho, fueron los miembros de este linaje los que constituyeron el ayllu o cacicazgo de los ingas e indios chinchaysuyo y establecieron un obraje de comunidad para su sobrevivencia; tanto los hombres como las mujeres del cacicazgo se apellidaban indistintamente como ingas o Yupanqui ${ }^{16}$ o Tocto $^{17}$ Las mujeres Tocto presuntamente están asociadas con la categoría de ser las primeras esposas del Inca, al menos en lo que atañe a la madre de Atahuallpa de nombre Tocto Coca — prima hermana de Huayna Cápac Ynga - y a la de su hijo Francisco Topatauchi, llamada Tocto Ocllo. ${ }^{18}$

14 Sobre el manejo del espacio del modelo cusqueño, véase: Miño (1994); respecto a la tenencia de tierras reales en el incario, consúltese Rostworowski de Diez Canseco (1962); Assadourian (1986); Zuidema (1997a).

15 Los descendientes directos de Atahuallpa vivieron durante el siglo XVI en el barrio de San Diego de la parroquia de indios de San Sebastián de Quito. Posteriormente San Diego pasó a ser jurisdicción de la parroquia de San Roque, la historiografía ha identificado al barrio de los miembros de la nobleza incaica con San Roque y no con San Diego, pero se trata de la misma propiedad.

$16 \quad$ Libra 1 MFN 9229.

17 Sobre Tocto como patronímico de hombres y mujeres en el ayllu de los ingas y chinchaysuyos, véase: Archivo Nacional de Historia, Quito, Cacicazgos: "Jacinta Allauca, cacica principal del pueblo de Pujilí del cacicazgo de la parcialidad Yngas Chinchasuyos, sobre el derecho que tiene a este cacicazgo", caja 4, expediente 3, Libra 1 MFN 0339; Archivo Nacional de Historia, Quito, Escribanías Públicas, Protocolos Notariales, Notaría Sexta, libro 88: "Venta de Juan Hidalgo a Fernando Tinajero, de unas tierras en Ituango", Libra 1 MFN 9062; Ituango estaba localizado en Cuturiví (Archivo Municipal 1941:27). Tocto también eran las plumas de color blanco de unos pájaros llamados yuco o guallatas que se criaban en los despoblados fríos y eran utilizadas para mochar o reverenciar al nuevo gobernante inca en la fiesta del Capay Raymi; las plumas también eran lucidas en la fiesta de camay quilla, o en los sacrificios, o en el proceso de entronización del nuevo inca; consúltese en el siguiente orden: Pizarro (1978 [1571]:241-242); Molina (1943 [1575]:61-63); Murúa [Morúa] (1987 [1611-13]:420); Cobo (1964 [1653]:138-139). Para González Holguín, las plumas blandas eran de unas aves jugosas y mantecosas que tenían lleno el cañón de sangre o manteca. De otra parte, Oliva (1998 [1631]: 141), menciona la existencia del pueblo Tocto en la provincia de Huaylas (Perú).

18 Según Sarmiento de Gamboa (1942 [1572]:166-167), Atahuallpa era hijo de Huayna Cápac Ynga y de Tocto Coca, su prima del linaje de Pachacuti Ynga Yupangui; Betanzos (1987 [1551-57]:193-194), mucho antes que Sarmiento de Gamboa, identificó a esta mujer con el linaje de Pachacuti Ynga Yupangui, pero la nombró como Palla Coca. La madre de Francisco 
El río de Patoa servía como límite natural de Cuturiví con las principales tierras del ayllu de los ingas e indios chinchaysuyo ubicadas en el pueblo de Conchacapac, y sus vecinos eran los miembros del ayllu de los cañarís de Aguallaca. Ambos lugares están situados al noreste y noroeste de Cuturiví, respectivamente. Un poco más hacia el norte vivían los indios collasuyo de Mulinliví - actual barrio de la Victoria- y al noreste, en cambio, residían los indios chugchilán, chan y pasto (Figura 2).

Los cañarís, collasuyo, chan y pasto son etnónimos de pueblos o naciones conquistados por los incas, en tanto que los indios chugchilán eran y siguen siendo parte de sigchos, un grupo étnico ubicado al noroeste de Pujilí (Figura 2), que fue sometido por Huayna Cápac Ynga y que durante la conquista española fue el último refugio de los incas quiteños.

La evidencia onomástica en Pujilí respecto a una continuidad histórica de larga duración es sugestiva, en razón de que Conchacapac, Aguallaca (cañarís), Collas (collasuyo), Chugchilán, Chan y San Juan de Pastocalle (pasto) siguen existiendo como barrios de Pujilí, pero también como pueblos en la misma provincia de Cotopaxi, tal es el caso de Pastocalle, Chan[chagua], Chan[tilín] y Chugchilán.

El Pujilí de los ingas, a su vez, estaba instalado entre dos cacicazgos de la élite indígena local, cuyos líderes fueron en los siglos XVI y XVII los indígenas más poderosos de la Audiencia de Quito: me refiero a los linajes de las familias Sancho Hacho de Velasco de Latacunga y los Ati de San Miguel de Salcedo; sus tierras incluían los pueblos de Saquisilí y Píllaro, respectivamente.

Sancho Hacho de Velasco o Tucomango fue el cacique de Latacunga que traicionó a sus pares Rumiñahui y Zopozo Pangue, al delatar a los conquistadores españoles sobre los movimientos militares de la resistencia en Sigchos. Por estas "buenas acciones" - aquí bien cabe la frase "o devoro o me devoran" - la Corona española le otorgó un escudo de armas, siendo de los pocos caciques de la Audiencia de Quito con este privilegio. Ni siquiera los miembros de la nobleza incaica tuvieron semejante prerrogativa, sobre la cual se basó su preeminencia política ante los demás caciques (Oberem 1993).

El representante más importante del linaje de los Ati fue Francisco García Ati, nieto de un indígena intruso originario del pueblo de Huapante en Salcedo que falsificó su genealogía para acceder al cacicazgo; su habilidad negociadora le facultó amasar una cuantiosa fortuna. Su testamento ${ }^{19}$ es impresionante, al punto de que su patrimonio es comparable con la del primer banquero de la

Topatauchi se llamaba Tocto Ocllo y era hermana de padre de Atahuallpa; véase Libra 1 MFN 9249, folios 72-72v y 87v. Tocto Ocllo también es mencionada como Payco Ocllo y sobrevivió a la conquista española con el nombre de Catalina.

19 Un traslado del testamento puede consultarse en: Archivo Nacional de Historia, Quito, Cacicazgos: "Guillermo García Ati, cacique principal y gobernador del pueblo de San Miguel, contra doña Lucía Ati Pusana", Quito, caja 4, expediente 1, Libra 1 MFN 0286. 
Audiencia de Quito, el mercader judío Cristóbal Martín ${ }^{20}$ quien a finales del siglo XVI controlaba el mercado monetario de esta jurisdicción. En mi criterio, Francisco García Ati fue el indígena más acaudalado de la Audiencia de Quito. Un siglo después de la conquista española, los descendientes de ambas ramas genealógicas, a través de matrimonios estratégicos concertados con sucesoras directas de Atahuallpa - la cuarta y quinta generación - buscaron su ascenso social fusionándose con la nobleza incaica, pero sus legítimas esposas al no tener hijos truncaron sus ambiciones y el linaje del último cápac inca del imperio se perdió. ${ }^{21}$

\section{El Pujilí de los ingas Según la historiografía}

El Pujilí de los ingas no ha sido objeto de un estudio específico. Son pocos los investigadores que mencionan al ayllu o cacicazgo de los ingas e indios chinchaysuyo, pero sin contemplar su potencialidad como elemento cohesionador de la nobleza incaica, la élite indígena local y otros ayllus o cacicazgos.

Gregorio Loza-Balsa, en un valioso trabajo inédito de 1975, demostró desde la arqueología evidencias contundentes sobre la presencia inca en el corregimiento de Latacunga, pero no se percató sobre la existencia del ayllu de los ingas e indios chinchaysuyo. Juan Carrera Colin (1981), desde la antropología, menciona a los ingas y chinchaysuyo asentados en Pujilí como dos grupos étnicos distintos establecidos por los incas, en razón de que en los documentos coloniales el vocablo chinchaysuyo siempre está asociado con la voz inga y la convivencia conjunta es por la estima que los inkas tenían al gran señorío de Chinchay. Piedad y Alfredo Costales (1982), en su libro clásico Los señores naturales de la tierra, reconstruyeron la genealogía de una parte de la nobleza incaica asentada en Pujilí pero, como bien subraya Espinosa Fernández de Córdova, su estudio:

[...] estropea el hecho de no enfrentar la brecha que separaba a los 'señores naturales' de las autoridades precolombinas; sintomáticamente ellos toman al 'señor natural' como un término objetivo que denota las autoridades tradicionales reales, y no como un estatus legal que signaba un fenómeno producido legalmente (Espinosa Fernández de Córdova 2015:34).

Desde la etnohistoria, en cambio, Udo Oberem (1993) puso el énfasis en la élite indígena asociada con esta nobleza, como fue el cacique Sancho Hacho de Velasco de Latacunga. Segundo Moreno Yánez (1995), en su artículo sobre las composiciones de tierras y el despojo de la propiedad indígena en Latacunga 
y Ambato, no hace referencia alguna a este cacicazgo. Por su parte, Bernard Lavallé (2001), sugiere que los ingas e indios chinchaysuyo fue el cacicazgo más "modesto" en el corregimiento de Latacunga, en el marco del alzamiento protagonizado por Francisco Zamora, un cacique local secuaz de Juan Santos Atahuallpa y de los movimientos neo-incas generados en el Perú durante el siglo XVIII. Eduardo Almeida Reyes (2013), a raíz del descubrimiento que realicé de las ruinas arqueológicas incas de Malqui-Machay, con base a pocas prospecciones arqueológicas superficiales y sustentado netamente en fuentes secundarias y sin un contexto etnohistórico adecuado, identificó patrones funcionales de la arquitectura ceremonial incaica en la provincia de Cotopaxi y realizó un análisis comparativo con el Cusco, para lo cual utilizó la propuesta de Teodoro Hampe Martínez (2013).

Para los autores que registraron la presencia de los ingas e indios chinchaysuyo en el corregimiento de Latacunga, su advenimiento fue un hecho anterior a la conquista española. Utilizando los mismos documentos que respaldaron los argumentos de estos autores y con apoyo de otras fuentes primarias inéditas, testimonios etnográficos, vestigios arqueológicos descubiertos recientemente y trabajo de campo sistemático, ${ }^{22}$ tomo distancia de este supuesto para discutir que el ordenamiento espacial del Pujilí de los ingas corresponde al período de la conquista española, mas no inca. En mi criterio, la nobleza incaica escogió de manera consecuente el sitio de Pujilí para refugiarse luego de la hecatombe de la conquista española, en tanto que la supremacía política y la riqueza económica de los caciques Ati de Salcedo y Sancho Hacho de Velasco de Latacunga, fueron efecto de un pacto colonial, mas no una vuelta al statu quo pre-inca o inca.

En otros términos, la permanencia de la nobleza incaica y el surgimiento de una élite indígena pujante en el corregimiento de Latacunga, deben ser analizados como parte del proceso de desestructuración ocasionado por el nuevo orden colonial. Para este caso específico, la lectura crítica de los documentos nos alerta sobre el peligro de extrapolar los datos ya que pueden conducir a lecturas anacrónicas.

Si en un documento del siglo XVII se menciona a los cañarís de Aguallaca en Pujilí, no significa que este grupo étnico haya sido una colonia de mitimaes trasplantados por Huayna Cápac Ynga cuando conquistó Latacunga; lo propio se aplica a los indios chinchaysuyo, chugchilán, pastos y chan, así como también a la nobleza incaica de Conchacapac, a la élite indígena local y, por supuesto, a los descendientes directos de Atahuallpa en Cuturiví. Nada más hay que percatarse que Pujilí, como centro urbano, es una reducción colonial;

22 Con el fin de validar el descubrimiento de las ruinas arqueológicas incas de Malqui-Machay en la comunidad académica nacional e internacional, desde el 16 de julio de 2004 en que se descubrieron los primeros vestigios en la hacienda Malqui hasta la presente fecha, se han realizado un total de 41 expediciones en la provincia de Cotopaxi y otros sitios vinculados. 
por eso se lo denomina "pueblo nuevo", aunque el topónimo corresponda a una lengua vernácula. ${ }^{23}$

El problema es cómo establecer la cronología de la existencia de tal o cual grupo étnico con base a los documentos de archivo, sean del período colonial o republicano, o fuentes etnográficas actuales, tomando en cuenta, además, las limitaciones metodológicas convenidas en las excavaciones arqueológicas, en razón de que la datación con carbono 14 sigue siendo insuficiente para conseguir fechas concluyentes e irrebatibles para períodos cortos como el del imperio inca que tiene más o menos 300 años de existencia, ya que el margen de error que se obtiene con este procedimiento oscila en este mismo orden temporal. En síntesis, por más sofisticados y refinados que sean los métodos de datación utilizados por la arqueología, no es viable poner una o más fechas para el período inca en el Ecuador aborigen —apenas 50 años_-, por lo que necesariamente tenemos que recurrir a otros mecanismos para reconstruir la influencia del imperio en estos territorios.

\section{UNA HIPÓTESIS SOBRE EL ORIGEN DE LOS INGAS DE CONCHACAPAC}

Conforme a Juan Pérez Bocanegra (1631:611-613), el rango de parentesco de la voz quechua concha corresponde a sobrino o sobrina; ${ }^{24}$ para Betanzos (1987 [1551-57]:132) "capac" quiere decir mucho más mayor que rey. Si seguimos fielmente a los autores citados, los conchacapac serían sobrinos de los gobernantes incas o "capac cuna"; 25 en el caso del Pujilí de los ingas, la filiación corresponde a Huayna Cápac Ynga, como se argumenta a continuación.

Para Cerrón-Palomino (2011:119-124), la voz "capac" es de procedencia puquina y su sentido original expresa nombre de jefe étnico, lo cual está bien sustentado; no obstante, en Quito — la última región conquistada por los incas - las fuentes de archivo de los siglos XVI y XVII dan cuenta de que el vocablo cápac como categoría o rango de mando es privativo de los descendientes directos de Huayna Cápac Ynga, así como el uso de Yupanqui

23 Posiblemente el topónimo Pujilí sea de influencia Panzaleo, lengua que hablaban los pueblos indígenas que fueron conquistados por los incas y que estaban ubicados entre Mulaló, al norte de Latacunga, y Mocha, al sur de Salcedo (Figura 2), véase: Ontaneda Luciano (2002:7)

24 El vocablo quechua concha asimilado a sobrino o sobrina también se encuentra en el Manuscrito de Huarochirí, capítulo 31 (Taylor 2008:129). Otra interesante interpretación propone Yánez del Pozo (2002:93-95, 100-105;166), para quien —inspirado en Isbell— los concha están asociados con el sacerdote del agua y son los que forcejean el control del líquido vital.

25 Según Betanzos (1987 [1551-57]:17), los capac cuna eran los señores orejones ingas del Cusco. 
o Yupangue como patronímico. Cerrón-Palomino (2011:125-129), también plantea que Yupanqui es una voz híbrida del aimara y el quechua, y significa persona honorable; cuestiona, además, el sentido que dio Betanzos (1987 [1551-57]:83) de ser personas ilustres y de alcurnia.

A diferencia del linaje de Huayna Cápac Ynga, la parentela de Atahuallpa adoptó como apellido su propio nombre Atahuallpa - con sus variantes en la forma escrita - y ninguno de sus descendientes fue referido como cápac o Yupanqui o Yupangue, pero sí como ingas.

Esta aclaración induce a eliminar del ayllu de los ingas e indios chinchaysuyo asentados en Conchacapac a la parentela directa de Atahuallpa, excepto por su madre, y centrarnos en un sobrino de Huayna Cápac Ynga que tuvo protagonismo político importante a raíz de la conquista española de Quito: me refiero a don Mateo Pangue o Mateo Ynga Yupangue o Yupanqui. ${ }^{26}$

Don Mateo Ynga Yupangue, en la probanza de méritos y servicios que presentó en 1563 para confirmar su nombramiento como alguacil mayor de la Audiencia de Quito, declaró que era hermano de Atahuallpa e hijo de Cápac Yupangue, quien era a su vez hermano de Huayna Cápac Ynga y ambos eran grandes amigos. ${ }^{27}$ Como se puede observar en don Mateo, las voces cápac y Yupanqui determinan su condición de nobleza. De hecho, en la lista de caciques que fueron educados por fray Jodoco Rique en el convento de San Francisco de Quito del año 1564, don Mateo encabeza la lista y de los 41 jefes étnicos sólo a él se nombra como Yupanqui o Yupangue (Moreno 1998:278-279).

La genealogía de don Mateo Ynga Yupangue es complicada y enredada, pero cruzando la información de archivo y la literatura de la época, queda claro que, si es hermano de Atahuallpa es porque tenían una madre en común, Tocto Coca, prima hermana de Huayna Cápac Ynga, mas no el mismo padre, Cápac Yupanqui. En este punto la propuesta lingüística de Cerrón-Palomino tiene asidero, ya que se puede asociar a Cápac Yupanqui con un jefe étnico de máxima jerarquía ${ }^{28}$ como, por ejemplo, Zopozo Pangue, el gobernador inca de Quito que alzó a Atahuallpa como cápac cuando la guerra contra Huáscar Ynga y posteriormente comandó, conjuntamente con Rumiñahui, la resistencia de los incas de Quito contra los conquistadores españoles. El hecho de que don Mateo utilice Pangue — posible error de transcripción de Yupanguecomo patronímico no es una coincidencia, si se considera que fue el heredero

26 Sobre la vida de don Mateo Ynga Yupangue, véase: Oberem (1976); Espinoza Soriano (2002).

27 La declaración sobre el grado de parentesco entre Cápac Yupanque y Huayna Cápac Ynga fue hecha por el testigo Francisco Yongopiña, cacique y señor de Chimbo, véase Libra $1 \mathrm{MFN}$ 9248 , folio $11 \mathrm{v}$.

28 Con el fin de abonar al sentido de cápac como jefe étnico, pero de estirpe noble o emparentado con los incas de la realeza, cargo que fue asimilado por los españoles como gobernador de un distrito espacial determinado, véase: Santillán (1968 [1563]:105); Cobo (1964 [1653]:207208). 
del señorío y las tierras de su padre, a quien —al igual que a Huayna Cápac Ynga - le tributaban todos los caciques e indios del Perú. Tenía, además, acceso a los depósitos, oro, mantas de algodón, coca, ají, maíz, papas, sal, ovejas, venados y conejos que había en el reino. ${ }^{29}$ Solamente un individuo con la categoría de segunda persona del inca podía acceder a semejantes prebendas, como probabilidad fáctica puede tratarse del gobernador inca de Quito, Zopozo Pangue. ${ }^{30}$

Otro dato vinculante constituye la presencia de mujeres Tocto en Conchacapac, condición que habría tenido la madre de don Mateo, de tal forma que su ascendencia por ambos lados pertenecía a la más alta nobleza incaica asentada en Quito. Esto se contrasta, además, con las relaciones cercanas entre don Mateo y Francisco Topatauchi, cuyas propiedades colindaban en el barrio de San Diego de la parroquia de indios de San Sebastián de Quito, y en el codicilo del auqui se menciona un legado para Antonio Alpui, hijo de don Mateo.

Pero no sólo los documentos de archivo dan cuenta sobre el uso del patronímico Yupanqui en Conchacapac: también en el trabajo de campo realizado se pudo constatar la recurrencia numerosa de moradores indígenas del sector que llevan el Yupanqui como apellido, lamentablemente ellos no pudieron dar razón sobre sus orígenes. ${ }^{31}$

La pregunta es: ¿Qué hacía la parentela de don Mateo Ynga Yupangue en Conchacapac del Pujilí de los ingas, tomando en cuenta que su lugar de residencia era el barrio de San Diego en la parroquia de indios de San Sebastián de Quito?

Don Mateo Ynga Yupangue, según lo asentado por varios testigos que declararon en la probanza, estuvo en el Cusco con Quisquis. ${ }^{32}$ Quisquis, conjuntamente con Calicuchima fueron los principales generales de las tropas de Atahuallpa que depusieron a Huáscar Ynga. Después de esta derrota, Quisquis —en el propio Cusco_ - obligó a Huáscar Ynga a rendirse frente al huauqui de Atahuallpa, una efigie que encarnaba al propio inca ${ }^{33}$ y que era llevada como el principal símbolo de las batallas:

[...] y llegados al llano de Quivipay [Quepaypan], ${ }^{34}$ se fueron sentando por su orden, haciendo una profunda reverencia a la imagen y estatua de Atavallpa en

Tanto Udo Oberem (1976), cuanto Waldemar Espinoza Soriano (2002) no se percataron de esta potencial concurrencia.

Trabajo de campo, expedición No. 26, 31/05/1/06/2013.

Libra 1 MFN 9248, folios 11-11v.

Dean (2010:32) plantea una lectura diferente sobre el significado del huauqui. Esta figura o efigie, que en quechua expresa "hermano", encarnaba al gobernante inca e implicaba su presencia inmediata y sin intermediarios, en contraste con el sentido de representación que sugiere reemplazo, substitución y subrogación.

34 Según el Inca Garcilaso de la Vega (1943b [1609]:289-290), el campo de la batalla es llamado de forma errónea como Quipaipan, el nombre correcto es Quepaipa que quiere decir 
señal de darle la obediencia, y sentados todos, luego los soldados de Quizquiz [...] los cercaron en torno y comenzaron a prender a los más señalados Ingas y Orejones, y el primero que allí se prendió [...] fue el infelice y mal fortunado Guanca-Auqui, y con él a Guapanti y a Paucarusno, capitanes suyos, prendieron luego a Apoc-Challco-Yupangui y a Pupaca (entrambos sumos sacerdotes del Sol) porque ellos habían sido los que habían dado a Guáscar-Inga las investiduras de rey, y juntamente con estos, otros muchos de menos calidad, aunque también de la sangre y linaje de Ingas. Y levantándose en pie el general Quizquiz [...] comenzó a afrentarlos y concluyó, con que usando de la clemencia, que a sí y a su valor debía, los perdonaba por entonces, y se satisfacía su justicia, con que a cada uno se le diese en las espaldas ciertos golpes con los chambis, que son cierta manera de mazas hechas de piedra; acabada esta benigna crueldad mandó matar a algunos, con quien él debía estar disgustado, y no tan presto era mandado cuan presto era obedecido.

Luego mandó pregonar que todos generalmente, volviesen el rostro hacia donde les demoraba el Quito, y adorasen y saludasen con altas y alegres voces a Atavallpa su señor, y así comenzaron a aclamar: $<<$ viva muchos años Atavallpa, nuestro señor Inga; el Sol, su padre, le acreciente la vida y la tierra le permita hollarla largo tiempo, y le ayude a regarla con la sangre de sus enemigos $>>$, y diciendo esto se pelaban la cejas y pestañas y las arrojaban hacia aquella parte en señal de sacrificio [...] (Cabello Balboa 1945 [1586]:423-424).

El huauqui de Atahuallpa fue confeccionado tiempo antes de la declaratoria de guerra entre los dos hermanos, cabalmente en el acto de entronización que tuvo lugar en el palacio de Carangue ${ }^{35}$ donde Atahuallpa —ante un bulto de Huayna Cápac Ynga que quedó en Quito- ${ }^{36}$ recibió la mascapaycha y tomó como pivihuarmi ${ }^{37}$ o legítima mujer a su prima hermana llamada Cuxirimay Ocllo, cuyo hermano, de nombre Cuxi Yupangue, actúo como el vilaoma ${ }^{38}$

"mi trompeta". Para Vázquez de Espinosa (1948 [1629]:547) la batalla tuvo lugar en el año 1528.

35 El palacio de Carangue o Caranqui está ubicado en la actual provincia de Imbabura en Ecuador, sobre su importancia, véase: Bray (2015).

36 La tradición sobre el bulto de Huayna Cápac Ynga que quedó en Quito está registrada desde el inicio de la conquista española, Francisco de Xerez (1985 [1534]:118-119), testigo de vista de esos acontecimientos, menciona que el cuerpo quedó en Quito, en tanto que la cabeza fue llevada al Cusco. Gonzalo Fernández de Oviedo (1959 [1548]:61), glosa el relato de Xerez y agrega que en muchos pueblos tenían figurada su persona de bulto. Betanzos (1987 [155157]:209) narra que Atahuallpa mandó hacer un bulto de su padre con un pedazo de su carne y ciertos cabellos y uñas, antes de que el cuerpo completo fuera adobado y llevado al Cusco para realizar las exequias ceremoniales.

37 Sobre el grado de parentesco entre Atahuallpa y Cuxirimay Ocllo y la elección de ésta como su pivihuarmi, véase: Betanzos (1987 [1551-57]:197-198).

38 Según Pedro Pizarro (1978 [1571]:90-91), el vilaoma pertenecía a la más alta nobleza incaica y era una suerte de obispo a quien todos obedecían y nada se hacía sin su licencia. Véase también Cieza de León (1996b [1553]:80-82). 
o sacerdote de la ceremonia de investidura. ${ }^{39}$ Toda vez que Atahuallpa se proclamó como señor del imperio, ordenó:

[...] hacer un bulto de sus mismas uñas y cabellos el cual imitaba a su persona y mandó que se llamase este bulto Ynga Guauquin que dice el hermano del Ynga y este bulto ansi hecho mandó que fuese puesto en unas andas y mandó a un criado suyo que se decia Chima que dando a este bulto que le sirviese y que tuviese cargo de guardarle y mirarle y dando este bulto otros muchos mozos y servicio mandó que luego fuese tomado el bulto y llevado en sus andas por la posta a do sus capitanes estaban Chalcuchima y Quizquiz para que las provincias y gentes que sujetasen diesen obediencia a aquel bulto en lugar de su persona y ansi fue este bulto llevado y dado a los capitanes los cuales les recibieron y holgaron y muy mucho con él e hiciéronles muy muchos y muy grandes sacrificios y ansi servían y respetaban a este bulto como si fuera allí en persona el mesmo Atahualpa [...] (Betanzos 1987 [1551- 57]:220).

Después de que Atahuallpa fue tomado prisionero en Cajamarca, para obtener su libertad dispuso a Cuxi Yupangue que fuera al Cusco a sacar los tesoros que servirían para pagar su rescate. Cumpliendo este cometido, Cuxi Yupangue, a su vez, demandó que el huauqui fuese puesto en cierta casa $^{40}$ para que todos reverenciasen y sirviesen a la imagen. Cuando llegó al Cusco

39 La mejor descripción sobre la ceremonia de entronización de Atahuallpa Ticci Cápac corresponde al cronista Juan de Betanzos (1987 [1551-57]:119-221), cuya informante fue Cuxirimay Ocllo. Después de que Atahuallpa fue ejecutado, Francisco Pizarro tomó como concubina a Cuxirimay Ocllo, cristianizada como Angelina Yupangue, con quien tuvo dos hijos. A la muerte de Francisco Pizarro, doña Angelina se casó con Betanzos.

40 Tal vez el huauqui de Atahuallpa fue venerado en ciertas casas que su ejército se habría apoderado cuando tomaron el Cusco, las que probablemente habrían sido utilizadas para su servicio y también para preparar la futura llegada del monarca a la capital del imperio. La referencia escrita más antigua sobre la ubicación de esta propiedad se encuentra en el relato que escribió Miguel de Estete (1968 [1535]:390), cuando conjuntamente con Francisco Pizarro entraron por primera vez al Cusco: " $[. .$.$] nos aposentamos en una plaza principal de$ ella, donde estaban las casas de Atabalica y de otros príncipes y señores que allí residían [...] Aquella casa de Atabalica que está en ella tenía dos torres de buen parecer, una portada rica chapada de piezas de plata y de otros metales que parecían bien. En la plaza habia una puerta donde había un monasterio que se llamaba Atuncancha [...]”. Pedro Pizarro (1978 [1571]:87-88), otro testigo de vista de los acontecimientos en Cajamarca, concuerda con Estete y proporciona datos adicionales: "El Marqués hizo aposentar [...] la xente alrrededor de la plaça, aposentándose él en Caxana, unos aposentos que heran [...] de Guaina Capa [...] la demás xente se aposentó en un galpón grande que estaua [...] xunto a la plaça, y en Hatuncancha, que hera un çercado grande que [...] tenía solo [...] una entrada por la plaça: / este çercado hera de mamaconas, y auía en él muchos aposentos". De ambas citas, se puede inferir que las posibles casas que Atahuallpa tuvo en el Cusco estaban localizadas junto al acllahuasi o templo de las mujeres escogidas, conocidas como mamaconas, véase Polo de Ondegardo (1917b [1560-72]:82). 
la primera delegación que Francisco Pizarro envió, Quisquis ordenó a Chima esconder el huauqui en Jaquijahuana ${ }^{41}$ (Betanzos 1987 [1551-57]:279-282).

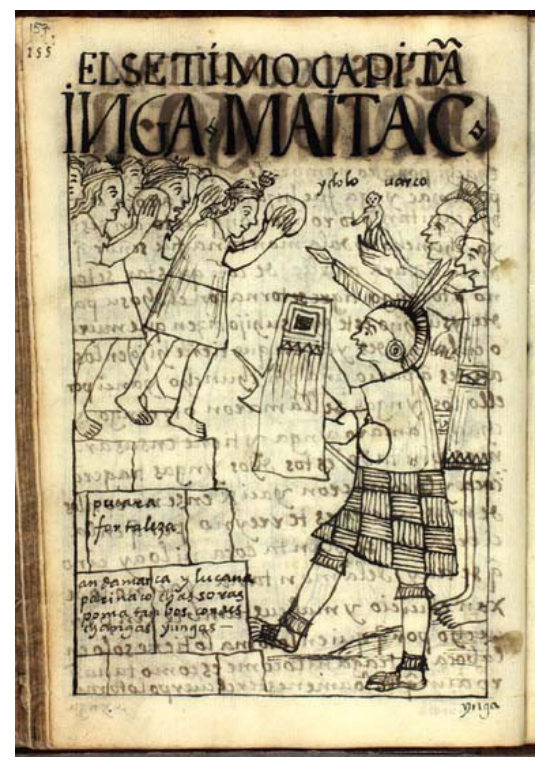

Figura 4. Resistencia ante un factible huauqui (Guamán Poma de Ayala 2004 [161516]:157).

No se sabe de qué material estaba confeccionado el huauqui de Atahuallpa, tampoco se conoce sobre la textura de algún otro huauqui que haya encarnado a determinado gobernante inca, en razón de que estas efigies "desaparecieron" a finales del siglo XVI, no obstante según el padre Bernabé Cobo (1964 [1653]:162-164), las estatuas llamadas guáuque o hermano podían ser del tamaño del propio inca o a su semejanza y algunas eran labradas de oro, otras de plata, palo o piedra o de otra materia.

Al poco tiempo de la ejecución de Atahuallpa, Francisco Pizarro y sus hombres tomaron el Cusco, y Quisquis con su ejército conformado por los huambracunas ${ }^{42}$ iniciaron la retirada hacia Quito. Lo más razonable es presumir

41 Jaquijahuana es un valle ubicado en Anta a $25 \mathrm{~km}$ del Cusco y es famoso por la batalla ocurrida en 1548, en la que el conquistador Gonzalo Pizarro y sus tropas se enfrentaron con el ejército realista, comandado por el pacificador Pedro de la Gasca.

42 Los huambracunas fueron los niños huérfanos que quedaron después de la matanza hecha por Huayna Cápac Ynga en Yahuarcocha, fueron ellos quienes conformaron el grueso del ejército que acompañó a Quisquis en la guerra contra el Cusco. 
que ellos llevaron consigo al huauqui de Atahuallpa que había sido ocultado en Jaquijahuana. Quisquis fue asesinado por los huambracunas en el pueblo de Chimbo, poco antes de llegar a Sigchos donde tenía previsto reunirse con Rumiñahui y Zopozo Pangue, en tanto que don Mateo "dio la obediencia a su magestad". ${ }^{43}$

La documentación estudiada sobre don Mateo deja entrever que este hombre fue testigo de vista del asesinato de Quisquis y vivió muy de cerca el holocausto de Zopozo Pangue — acaso su padre —, Rumiñahui y los demás incas de la resistencia contra los conquistadores españoles, testimonios que tal vez transmitió al cronista Miguel Cabello Balboa (1945 [1586]:381), cuando fue su informante.

Pero don Mateo también guardó muchos secretos. Su vida fue una encrucijada dolorosa, basta con ver su mirada triste en una escena de una copia de un cuadro al óleo que fue pintado en el siglo XVI, y que se conserva en el convento e iglesia de San Francisco de Quito.

La escena de la Figura 5 posiblemente corresponde a 1534-1535. En el centro, fray Jodoco Rique está bautizando a Francisco Topatauchi, el auqui hijo de Atahuallpa; a la derecha está don Mateo Ynga Yupangue junto a su esposa, doña Angelina Comenzana - hija del cacique Collahuazo, señor de Quitoque lleva en sus brazos a su hijo Antonio Alpuio. El personaje de la izquierda podría ser Tucomango o Sancho Hacho de Velasco, el cacique de Latacunga que traicionó a sus pares Rumiñahui y Zopozo Pangue, el gobernador inca de Quito y probable padre de don Mateo. ${ }^{44}$

¿Qué cosa excepcional podía don Mateo Ynga Yupangue salvar de la inmolación de los conquistadores españoles, después de someterse al rey de los cristianos? Como conjetura, sospecho que fue el huauqui de Atahuallpa, efigie que seguramente celaron los indios conchacapac del Pujilí de los ingas $\mathrm{y}$ es posible que haya sido honrada en las "tierras del Sol". Mi argumento es que las "tierras del Sol" eran parte de la misma propiedad de Cuturiví de Francisco Topatauchi y estaban ubicadas en una pequeña planicie donde los padres jesuitas terminaron de edificar en el año de $1743^{45}$ la capilla en honor al Divino Niño de Isinchi. La capilla se construyó en un feudo que usurpó la familia Loma Portocarrero a doña Mencia Inga, a finales del siglo XVII, cuando ésta fungía como cacica principal de los ingas e indios chinchaysuyo y

$43 \quad$ Libra 1 MFN 9248, folio 7v. Libra 1 MFN 9248, folio 7v. Es factible que por este acto de rendición, a don Mateo le hayan nombrado cacique de Chimbo (Moreno 1998:279). Sobre el asesinato de Quisquis.

44 La identificación de ciertos personajes y el título dado al cuadro, recaen en mi interpretación personal, apoyada en el estudio que he realizado acerca de la presencia inca en el Ecuador aborigen y colonial. La fotografía es de Karla Gachet, a quien reconozco su generosidad por ceder los derechos sobre la publicación de la misma. Referencia trabajo de campo, expedición No. 18, 13-15/08/2012.

45 Así consta en la fachada de la iglesia. 
gobernadora de Pujilí. Mediante engañosos agasajos y convidando aguardiente a doña Mencia para emborracharla, el capitán Ventura Loma Portocarrero y su apoderado, el gobernador Francisco Abad de Cepeda, la obligaron a otorgar la escritura de venta sobre este dominio; en el acto también intervinieron ciertos sacerdotes, clérigos y religiosos del orden de predicadores que "rogaron" a la susodicha para que firmara el instrumento jurídico que facultaba el traspaso de la propiedad; el fraude se realizó a través de un intérprete, aduciendo que ella era "incapaz e ignorante" y la disputa por las posibles "tierras del Sol" duró casi un siglo. ${ }^{46}$

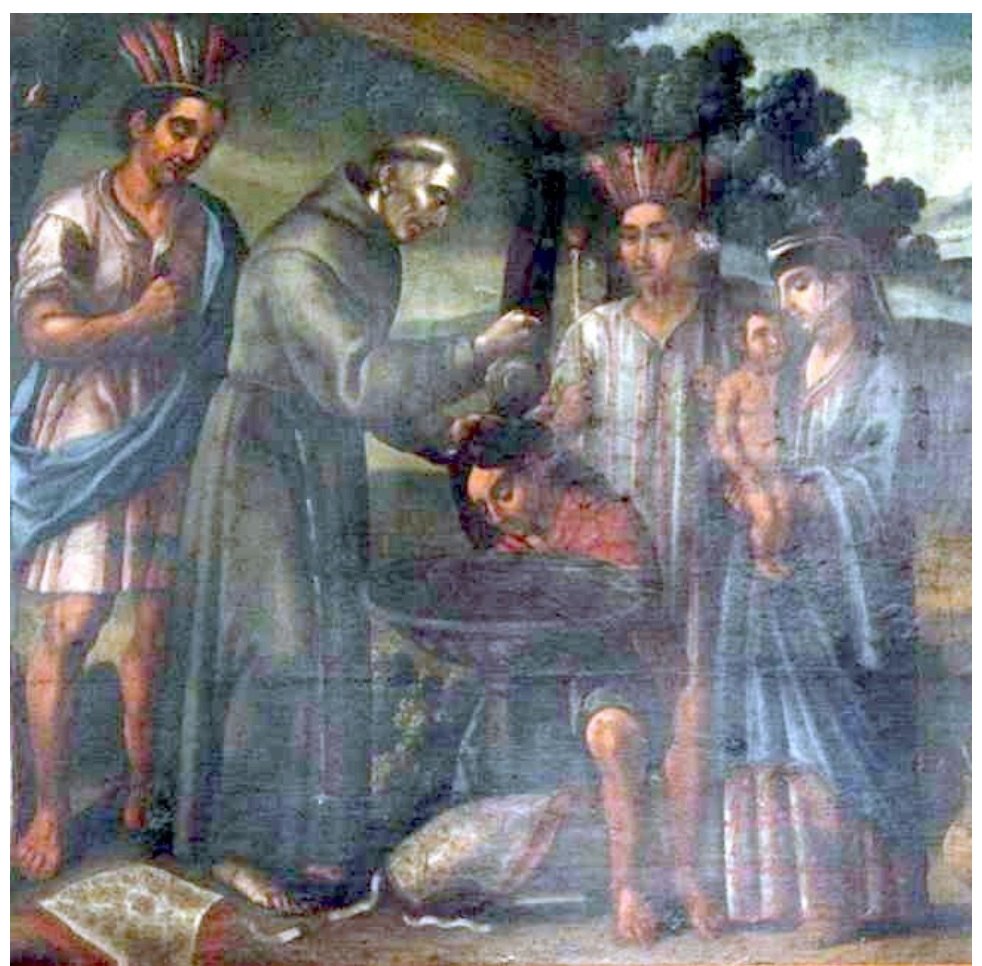

Figura 5. "El pacto colonial".

Efectivamente, en este litigio de larga duración también intervino la familia Sánchez de Orellana del marquesado de la casa de Solanda que,

46 El juicio se inició en 1687; véase: Archivo Nacional de Historia, Quito, Sección General, Serie Juicios Civiles: "Mencia Ynga, cacica principal del pueblo de Pujilí con Ventura Loma Portocarrero", caja 2: expediente 15, Libra 1 MFN 0586. 
en 1714 , ya estaba en posesión de la propiedad. ${ }^{47}$ Tanto las familias Loma Portocarrero y los Sánchez de Orellana tenían afinidad con los padres jesuitas. Francisco Abad de Cepeda, el apoderado de Ventura Loma Portocarrero, era deudo del rector de la Compañía de Jesús de Quito ${ }^{48}$ y el familiar titular del Santo Oficio de la Inquisición, corregidor y Justicia Mayor del asiento de Latacunga, era el mismísimo general Pedro Diez Sánchez de Orellana. ${ }^{49}$

La imagen católica del Divino Niño de Isinchi — una escultura de figura humana tallada en madera - tiene un mito de origen onírico. La tradición cuenta que, a principios del siglo XVIII, en un fardo de lana que traían los indígenas para el obraje de Isinchi se cayó una figura "pequeñita"; el patrón la confundió con un "muñeco" y la dejó allí para que los niños jueguen con él. El patrón tuvo repetidos sueños en los que el "muñeco" le pedía quedarse en la localidad y que él y sus allegados le construyeran una casa. El patrón hizo eco a la súplica del "muñeco" y fue así como se levantó un templo para venerar a la imagen católica "milagrosa" que "habló" al patrón. ${ }^{50}$

Otro relato sobre el origen del Divino Niño de Isinchi se pudo recopilar en la actual comuna de Cuturiví Grande. Según sus dirigentes, Agustín Ayala Copara y Juan Manuel Vega Toaquisa, en la carga de la mula había una piedra que colgaba y ahí estaba el muñeco; eran dos parejas de hermanos, pero en realidad era uno solo, el muñeco creció y le llamaban al hermano "huauque" y era de marfil. ${ }^{51}$ También nos mostraron tres piedras grandes que son objeto de ritualidad entre ellos: Hatun Rumi, Cula Rumi y Hambato Rumi. Son piedras "mansas", pero antes morían allí muchos niños o se enfermaban o “desaparecían", por eso ellos las asocian con el miedo. En el trabajo de campo se recogió asimismo un testimonio de un morador del pueblo de Conchacapac: para Luis Enrique Caiza Arias el "niñito" de Isinchi era pequeñito, no como el de ahora y "aparecía" y "desaparecía". 52

La capilla del Divino Niño de Isinchi fue construida con piedras talladas y pulidas al estilo inca y en un costado no anexo a esta construcción aún

$47 \quad$ El pleito de larga duración consta en Libra 1 MFN 9229.

48 Véase: Archivo Nacional de Historia, Quito, Escribanías Públicas, Fondo Protocolos Notariales, Notaría Tercera, libro 26: "Nombramiento de obra pía del padre Diego Abad de Cepeda, rector del Colegio de la Compañía de Jesús de Quito”, folios 587v-588, Libra 1 MFN 4219.

49 Véase: Libra 1 MFN 9229.

50 Sobre la tradición del origen del Divino Niño de Isinchi y otras leyendas de Pujilí, véase: Ramírez de Velóz (1994:78-79).

51 Es dable que se trate de un material similar al marfil, en razón de que éste fue introducido por los españoles al continente americano, podría ser tagua o hueso o algún otro material que semeje un color parecido.

52 Trabajo de campo, expediciones Nos. 17, 28/06/2012, y 26,31/05/1/06/2013, respectivamente. Sobre una interpretación acerca del significado de estas piedras, véase: Morales (2002:98100). 
permanece un muro de mampostería con nichos de forma trapezoidal. Asimismo, en el contorno de todo el complejo del santuario yacen en el suelo piedras almohadilladas encubiertas por la maleza; ${ }^{53}$ sin lugar a dudas se trata de evidencias materiales concretas de una construcción importante de procedencia inca que debió haber existido en el pasado, seguramente un templo dedicado al culto del Sol, pero también a la $h u a c a^{54}$ tutelar de la descendencia de Atahuallpa, cuyo huauqui era custodiado por el ayllu de los ingas e indios chinchaysuyo asentados en Conchacapac y honrado en uno de los nichos.

Curiosamente, la capilla del Divino Niño de Isinchi es el único santuario católico privado con carácter de peregrinación que existe en Ecuador y los documentos revelan, además, que la propiedad se traspasaba o enajenaba siempre con la imagen cristiana. ${ }^{55}$ También se destaca que Cuturiví y el santuario del Divino Niño de Isinchi hasta hace pocos años formaban un solo cuerpo como bien patrimonial y desde la época de los incas, pasando por la conquista española, el período colonial, los movimientos independentistas, la revolución liberal y hasta la presente fecha la propiedad ha estado vinculada con la élite política indígena, criolla y mestiza (Tabla 1), personalidades que al margen de sus diferencias políticas, culturales, religiosas y hasta raciales, han sido garantes de una tradición vigorosa como la del danzante de Pujilí o el sacerdote de la lluvia, declarado patrimonio cultural intangible de Ecuador. ${ }^{56}$

53 Sobre estos vestigios, véase el vínculo de Internet </https:/www.youtube.com/ watch?v=uRFVf2p3j4k/>

54 La huaca, según Taylor (2008:19) podía ser un “[...] ser sagrado (masculino o femenino); la manifestación de dicho ser sagrado y el santuario donde se practicaba su culto".

55 Sobre la enajenación de la propiedad con la imagen católica del Divino Niño de Isinchi, véase: Archivos Cotopaxi (Latacunga-Salcedo), Notaría Tercera, "Escritura de partición de Amada Calero", Libra 1 MFN 9239.

56 El danzante de Pujilí es una figura principal en la fiesta popular y ha inspirado una fecunda literatura, pero en ninguno de estos trabajos o investigaciones se advirtió sobre el vínculo ineludible con el ayllu de la nobleza incaica que sobrevivió a la conquista española en el Pujilí de los Yngas. El padre Marco Vinicio Rueda (1982) realizó un buen acercamiento al tema de las fiestas religiosas campesinas; a pesar de que su enfoque proviene de la antropología religiosa, el análisis se nutrió de los cronistas de Indias que constituyeron la base histórica para explicar las raíces de las distintas celebraciones y cómo los indígenas reprodujeron su cosmovisión simbólica en lo que se ha denominado la "fiesta popular". Ricardo Muratorio (1985) realizó una valiosa descripción pormenorizada de los danzantes de Corpus Christi, personajes que fueron concebidos como una tradición cultural de los indígenas de la sierra de Ecuador, pero no hay relación alguna a su origen histórico. Marcelo Naranjo Villavicencio (1996:70-71) recogió dos versiones similares de la leyenda sobre el origen del Niño de Isinchi e identificó erróneamente al obraje como propiedad de los padres jesuitas por el hecho de que la capilla fue construida por esta orden religiosa; su apreciación acerca de la devoción que genera esta imagen y otras registradas en la provincia de Cotopaxi, es que son " $[\ldots]$ producto del folclor y la imaginación popular, independientemente de la intencionalidad de quien en primer lugar trajera la imagen o la hiciera tallar" y repara que el tema de la religiosidad popular exige un nivel de investigación más profundo. Una acertada evaluación historiográfica sobre la fiesta popular tradicional en el Ecuador puede consultarse 
Tabla 1

La élite política indígena, criolla y mestiza en Cuturiví e Isinchi

\begin{tabular}{|c|c|c|c|}
\hline $\begin{array}{l}\text { Siglos } \\
X V I-X V I I\end{array}$ & $\begin{array}{l}\text { Francisco Topatauchi el auqui, } \\
\text { hijo del último emperador del } \\
\text { Tahuantinsuyo; el único ayllu } \\
\text { de la nobleza incaica en la } \\
\text { Audiencia de Quito }\end{array}$ & $\begin{array}{l}\text { Élite política } \\
\text { indígena }\end{array}$ & $\begin{array}{l}\text { Imperio inca, } \\
\text { conquista española, } \\
\text { período colonial }\end{array}$ \\
\hline $\begin{array}{l}\text { Siglos } \\
X V I I I-X L X\end{array}$ & $\begin{array}{l}\text { Familia Sánchez de Orellana } \\
\text { del marquesado de Solanda, } \\
\text { corregidor de Latacunga; la } \\
\text { última heredera se casó con } \\
\text { el mariscal de Ayacucho, } \\
\text { Antonio José de Sucre }{ }^{57}\end{array}$ & $\begin{array}{l}\text { Élite política } \\
\text { criolla y mestiza }\end{array}$ & $\begin{array}{l}\text { Período colonial y } \\
\text { movimientos de la } \\
\text { independencia de } \\
\text { España }\end{array}$ \\
\hline $\begin{array}{l}\text { Principios del } \\
\text { siglo } X X\end{array}$ & $\begin{array}{l}\text { General Leónidas Plaza } \\
\text { Gutiérrez, } \\
\text { constitucional del Ecuador }{ }^{58}\end{array}$ & $\begin{array}{l}\text { Élite política } \\
\text { mestiza }\end{array}$ & Revolución liberal \\
\hline $\begin{array}{l}\text { Finales del } \\
\text { siglo XX hasta } \\
\text { la presente } \\
\quad \text { fecha }\end{array}$ & $\begin{array}{l}\text { Bolívar León Lara, primo } \\
\text { hermano y cuñado del general } \\
\text { Guillermo Rodríguez Lara, } \\
\text { jefe de Estado del Ecuador }{ }^{59}\end{array}$ & $\begin{array}{l}\text { Élite política } \\
\text { mestiza }\end{array}$ & $\begin{array}{l}\text { Dictaduras } \\
\text { militares }\end{array}$ \\
\hline
\end{tabular}

En la actualidad la fiesta más importante que se celebra en Pujilí es la de Corpus Christi que se inicia con la extraordinaria y solemne entrada del Divino Niño de Isinchi a la plaza principal del pueblo: la imagen católica es escoltada por llamas vestidas y transportada por los fieles en una urna colocada encima de unas andas decoradas con flores; en el trayecto de su viaje, vistosos arcos triunfales anuncian su paso majestuoso, orquestado por músicos que tañen trompetas, flautas y pingullos, en medio de cantos alusivos al niño milagroso. ${ }^{60}$

en José Pereira Valarezo (2005). Un excelente aporte para el conocimiento de la fiesta de la Mama Negra de Latacunga, que se retroalimenta con algunos personajes de la fiesta de Corpus Christi de Isinchi, constituye la obra de Marco Karolys Baca y Juan Ubilla Freire (2008), quienes reconocieron ciertas prácticas de procedencia inca en esta celebración, pero sin lugar a dudas su mayor contribución constituyen los magníficos dibujos en plumilla que aluden al lenguaje de la fiesta.

57 La familia Sánchez de Orellana fue una de las más acaudaladas de la Audiencia de Quito en el siglo XVIII, consúltese Herzog (1994 y 1996); Büschges (2007:170-172).

58 Véase: Ruiz Navas (2006:143).

59 Archivos Cotopaxi (Latacunga-Salcedo), Notaría Primera, "Escritura de venta: Trajano Alfonso Calero Noroña a favor de Bolívar León Lara", Libra 1 MFN 9237.

60 Sobre la entrada del Divino Niño de Isinchi a la fiesta del Corpus Christi en Pujilí, véase el vínculo de Internet $</$ https://www.youtube.com/watch?v=uRFVf2p3j4k/>. 
Al Divino Niño de Isinchi le reciben comparsas de danzantes que representan a distintas comunidades indígenas del sector y en ocasiones le engalanan con un atuendo provocador como si fuera el propio Inca. Las tres potencias son reemplazadas por un tocado que semeja a la mascapaycha y en el centro del vestido está bordada la chacana (Figura 6). La imagen católica, insólitamente puede ser "arrendada" por los moradores de la provincia y otros lugares más remotos como los pueblos de Salcedo y Píllaro de la provincia de Tungurahua: esto explica por qué el Divino Niño de Isinchi tiene el calificativo de "niño viajero". En efecto, la imagen acostumbra a visitar a las comunidades indígenas y a sus feligreses y es tal la fuerza de la devoción que genera el Divino Niño de Isinchi que al interior de un cuarto, contiguo a la capilla, se encuentran miles de ex votos que intermedian por algún milagro de los creyentes, quienes canalizan su fe con dádivas consistentes básicamente en prendas de vestir para la imagen, cuyo ajuar supera los cinco mil trajes. ${ }^{61}$

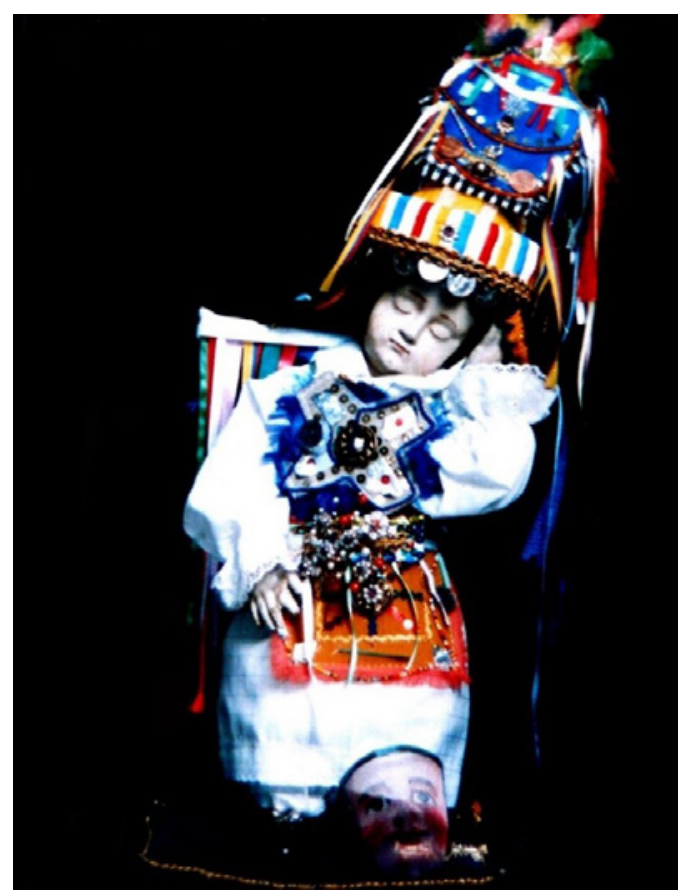

Figura 6. E1 Divino Niño de Isinchi vestido con un atuendo al estilo inca. 
El origen onírico del Divino Niño de Isinchi — como insinúa la tradiciónestá permeado por el principio simbólico del doble o del hermano - huauqui en su lengua materna - que remite a una figura original mucho más pequeña de algún material parecido al marfil, tal vez de yeso como aquellas que Pedro Sancho de la Hoz, observó en el Cuzco. ${ }^{62}$ Que el muñeco "aparezca" y "desaparezca" y "crezca" al mismo tiempo no es inocente: esta metamorfosis bien puede ser asociada con la presencia indirecta, discreta y firme de los padres jesuitas ${ }^{63}$ quienes orquestaron la venta del predio en Isinchi y permitieron que se emborrachara a su propietaria para garantizar por instrumentos jurídicos la exterminación del culto pagano que generaba el huauqui de Atahuallpa y que desafiaba y atentaba contra los preceptos de la "verdadera" religión. En teoría, el ídolo que encarnaba al hijo del Dios Sol —al margen del material que haya sido utilizado para su hechura - debía ser reemplazado por la escultura de madera que representaba al hijo del Dios de los cristianos; en la práctica, es factible que el huauqui de Atahuallpa fuera trastocado por la imagen del Divino Niño de Isinchi para ser venerada en una capilla levantada con las mismas piedras del templo de los "infieles". Pero los "infieles" no dejaron de adorar a sus divinidades, ahí están inamovibles en el tiempo y el espacio Hatun Rumi, Cula Rumi y Hambato Rumi, tres monolitos identificados con la muerte de infantes, lo cual produce temor entre sus moradores, quizá como una reminiscencia del pasado más remoto de la desgarradora práctica de la capacocha o el sacrificio de niños y niñas que acostumbraban hacer los incas a sus dioses e ídolos. ${ }^{64}$

Entre los incas, las piedras tenían un sentido animista y podían albergar el alma, el espíritu o el respiro de un ser viviente, de hecho eran el perfecto medium de la personificación o encarnación de esa persona (Dean 2010:33). Las piedras - al igual que el cuerpo y el huauqui de cada gobernante incaeran objeto de adoración y sacrificios, así lo registró en 1571 el licenciado Juan Polo de Ondegardo, cuando identificó 328 huacas de los indios del Cusco

62 Cuando Sancho de la Hoz (1968 [1534]:334) entró al Cusco, quedó embelesado por el culto de que eran objeto los cuerpos muertos de los ingas, ya que se percató sobre la existencia de "[...] otras imágenes hechas de yeso o de barro, las que solamente tienen los cabellos y uñas que se cortaba y los vestidos que se ponía en vida, y son tan veneradas entre aquellas gentes como si fueran sus dioses".

63 Sobre la participación de la Compañía de Jesús en los procesos de extirpación de idolatrías en el Perú colonial, véase el estudio introductorio hecho por Duviols, para quien "Los jesuitas no tenían la obsesión de la hispanización de la 'política cristiana' como la tenía Toledo, y eran partidarios de conservar muchas costumbres indígenas, siempre que éstas no fuesen contrarias a la fe y a la "ley natural"' (1986:L). También consúltese el interesante artículo de Mujica Pinilla (2005), sobre el culto que impulsaron los padres jesuitas al Niño Jesús Inca en el Cusco virreinal.

64 Sobre el sacrificio de la capacocha, véase: Cieza de León (1996b [1553]:89); Sarmiento de Gamboa (1942 [1572]:70); Molina, el cusqueño (1943 [1575]:69-71). 
dispuestas en los trayectos de los cuatro ceques ${ }^{65}$ que salían de la ciudad. De estas huacas (Tabla 2), 16 corresponden a conjuntos de tres piedras que estaban ubicadas en su mayoría en pequeños cerros y en donde se ofrendaban niños y niñas, uno de los adoratorios más solemnes era Chuquipalta que tenía tres piedras que representaban a Pachayachachi, Intiillapa y Punchao. ${ }^{66}$

\section{Tabla 2}

\begin{tabular}{lccc}
\hline Camino & Ceque & Huaca/No. & \multicolumn{1}{c}{ Descripción } \\
\hline Chinchaysuyo & 4 & Chuquipalta (8) & $\begin{array}{l}\text { Cerro junto a la fortaleza [Sacasahuaman en } \\
\text { el cual estaban tres piedras en representación } \\
\text { de Pachayachachic, Intiillapa y Punchao, } \\
\text { se ofrecían sacrificios de niños y niñas y de } \\
\text { figuras pequeñas, quemábase ropa y carneros, } \\
\text { era tenido como adoratorio muy solemne }\end{array}$ \\
\hline
\end{tabular}

\begin{tabular}{lcll}
\hline $\begin{array}{l}\text { Antisuyo } \\
\text { Payan }\end{array}$ & 5 & $\begin{array}{l}\text { Rondoya/ } \\
\text { Runtuyan (9) }\end{array}$ & $\begin{array}{l}\text { Tres piedras en el cerro del mismo nombre, } \\
\text { las puso allí el Inca Pachacútic y mandó las } \\
\text { adorasen }\end{array}$ \\
\hline Ayarmaca & 8 & Sauraura (5) & $\begin{array}{l}\text { Tres piedras que estaban en el pueblo de } \\
\text { Larapa }\end{array}$ \\
\hline $\begin{array}{l}\text { Collasuyo } \\
\text { Cayao }\end{array}$ & 1 & Churucana (3) & $\begin{array}{l}\text { Cerro pequeño y redondo junto a San Lázaro, } \\
\text { encima del cual estaban tres piedras tenidas } \\
\text { por ídolos, le ofrecían lo ordinario y también } \\
\text { niños, para que el sol no perdiese sus fuerzas }\end{array}$ \\
\hline
\end{tabular}

65 Tom Zuidema (1995:67), elaboró una propuesta teórica sobre los ceques, su fuente principal fue la crónica del padre Bernabé Cobo [1653], que a su vez glosó la información de Juan Polo de Ondegardo [1571]. Se trata de una relación en que se describen “[...] 328 lugares sagrados del Cuzco y sus alrededores, que incluyen piedras, manantiales o casas que, por una razón u otra, fueron de particular relevancia en la historia o en la mitología inca. Estos sitios estaban divididos en grupos, cada uno de los cuales se concebía como dispuesto en una línea imaginaria llamada ceque. Es importante señalar que todas estas líneas convergían en el centro del Cuzco. Además, el mantenimiento y culto de los sitios distribuidos a lo largo de estas líneas estaban asignados a ciertos grupos sociales".

66 Según Cristóbal de Molina (1943 [1575]:25-26) Punchao Inca era el ídolo del Sol, Pachayachachi era otro ídolo con figura de hombre que quiere decir el hacedor. Para Cobo (1964 [1653]:160-161) Intiillapa, era la estatua en honor del trueno, Pachacuti Ynga Yupangui la "[...] tomó por hermano, y mientras vivió la trajo consigo en la guerra. Fué tenido este ídolo en gran veneración y servido con grande majestad y aparato". 
Continuación de Tabla 2

\begin{tabular}{|c|c|c|c|}
\hline Camino & Ceque & Huaca / No. & Descripción \\
\hline \multirow{5}{*}{ Payan } & 2 & Tuino Urco (6) & $\begin{array}{l}\text { Tres piedras que estaban en un rincón del } \\
\text { pueblo de Cacra }\end{array}$ \\
\hline & 5 & Tocacaray (6) & $\begin{array}{l}\text { Cerro frontero de Quijalla, había tres piedras } \\
\text { veneradas, se sacrificaban niños }\end{array}$ \\
\hline & 5 & Intipampa (7) & $\begin{array}{l}\text { Llano junto a Cacra, en medio del cual } \\
\text { estaban tres piedras, se sacrificaban niños }\end{array}$ \\
\hline & 5 & Omotourco (10) & $\begin{array}{l}\text { Cerro pequeño enfrente de Quispicanche, } \\
\text { encima estaban tres piedras, se ofrecían } \\
\text { sacrificios }\end{array}$ \\
\hline & 8 & Cuicosa (5) & $\begin{array}{l}\text { Tres piedras redondas que estaban en un } \\
\text { cerro junto a Guanacáuri }\end{array}$ \\
\hline \multirow{5}{*}{ Collana } & 3 & Sinopampa (7) & $\begin{array}{l}\text { Tres piedras redondas que estaban en un llano } \\
\text { en medio del pueblo de Sano, le sacrificaban } \\
\text { niños }\end{array}$ \\
\hline & 6 & Cuipan (6) & Tres piedras puestas en el llano de Quicalla \\
\hline & 6 & Quiquijana (9) & $\begin{array}{l}\text { Cerrillo pequeño donde estaban tres piedras, } \\
\text { le ofrecían solo conchas y ropa pequeña }\end{array}$ \\
\hline & 9 & $\begin{array}{l}\text { Tampucancha } \\
\text { (1) }\end{array}$ & $\begin{array}{l}\text { Parte de la casa de Mancio Sierra, en que } \\
\text { había tres piedras adoradas por ídolos }\end{array}$ \\
\hline & 9 & $\begin{array}{l}\text { Callaocachiri } \\
\text { (11) }\end{array}$ & $\begin{array}{l}\text { Tres piedras que estaban en un cerrillo del } \\
\text { mismo nombre, era adoratorio antiguo, se } \\
\text { sacrificaban niños }\end{array}$ \\
\hline $\begin{array}{l}\text { Cuntisuyu } \\
\text { Anaguarque }\end{array}$ & 1 & Quiguan (15) & $\begin{array}{l}\text { Tres piedras que estaban en un portezuelo } \\
\text { camino de Pomacancha }\end{array}$ \\
\hline Collana & 4 & Amarocti (2) & $\begin{array}{l}\text { Tres piedras que estaban en un poblezuelo } \\
\text { llamado Aytocari }\end{array}$ \\
\hline
\end{tabular}

Registro de huacas de tres piedras en los cuatro ceques que salían del Cusco, según Juan Polo de Ondegardo (1971a [1571]:3-43) y el padre Bernabé Cobo (1946[1653]:169-186).

Una difícil disyuntiva debió haber sido para los miembros de la Iglesia católica constatar que, a finales de los siglos XVII y principios del XVIII, aún existía un foco de idolatría clandestina y subyacente nada más y nada menos que en el único ayllu de la nobleza incaica quiteña. Será por eso que astutamente los padres jesuitas estimularon la fábula del crecimiento "milagroso" del Divino 
Niño de Isinchi y, como paliativo para el cambio estructural que producía la evaporación de la imagen original, permitieron que los ingas e indios chinchaysuyo continuaran con sus prácticas tradicionales, como aquella del "niño viajero" que trajinaba para saludar a los feligreses, al igual que lo hacían las momias y huauquis de los incas en el Cusco colonial cuando visitaban a sus parientes ${ }^{67} \mathrm{o}$ la de ataviar a la escultura católica con un ajuar transgresor e híbrido de la posconquista española (Figura 6).

No debe asombrar que este ambiente también haya atrapado a la figura del danzante de Pujilí o el sacerdote de la lluvia, un personaje que, con su presencia, legítima el espectáculo de la fiesta del Corpus Christi y otras celebraciones católicas. La pieza más importante del traje del danzante de Pujilí es el tocado que lleva encima de su cabeza. Se trata de un adorno que simula la silueta de un árbol —malqui en quechua - ${ }^{68}$ con cuatro puntas o ramas estilizadas a cada lado, pero que está recargado de adornos al estilo barroco que cambian con la moda imperante, aunque la estructura en forma de árbol permanece invariable y detrás de ella hay un coda encriptado que debe ser descifrado con base a una lectura que contemple su origen histórico, más allá de su atractivo etnográfico.

A manera de hipótesis especulativa, se podría sugerir que el tocado del danzante de Pujilí que semeja a un árbol, bien podría ser un dispositivo mnemotécnico promovido por el ayllu de los ingas e indios chinchaysuyos para organizar la memoria histórica de los miembros del grupo étnico identificados con Atahuallpa, el ancestro fundador del único ayllu de la nobleza incaica en la Audiencia de Quito, y cuyo mito de origen se refiere al viaje épico que habrían realizado los cuatro hermanos con sus cuatro hermanas cuando salieron de la cueva de Pacaritambo hacia el Cusco. Curiosamente el tocado del danzante de Pujilí, también tiene la misma forma del diagrama genealógico que concibió Juan Pérez Bocanegra (1631) para ayudar a los curas a difundir la doctrina cristiana que prohibía casarse más allá del cuarto grado de parentesco, práctica que no era parte de la cosmovisión indígena, ya que las relaciones de matrimonio entre los incas, por ejemplo, consideraba el casamiento con la esposa-hermana. Y aunque el diagrama genealógico si bien es cierto tiene un origen judeocristiano y fue utilizado en la Europa medieval (Duviols 1997:129-130), no deja de sorprender la similitud con el tocado en forma de árbol (Figura 7). ${ }^{69}$

67 Sobre la costumbre de irse a visitar los muertos unos a otros y las celebraciones que se hacían, véase Pizarro (1978 [1571]:52-53).

68 Según Itier (2010:192), la voz mallki se refiere a todo vegetal plantado o destinado a ser trasplantado; en sentido figurativo es el ancestro fundador de un ayllu y de su territorio, metafóricamente es plantado por él y produce frutos que son sus descendientes.

${ }_{69}$ Sobre las implicaciones teóricas del diagrama de Pérez Bocanegra en el lenguaje del parentesco que propuso Tom Zuidema (1989:33-116) y que tuvo eco en la historiografía, por ejemplo Isbell (1997:273-283), véase el debate entre Duviols (1997) e Itier (1997) contra Zuidema (1997b). 

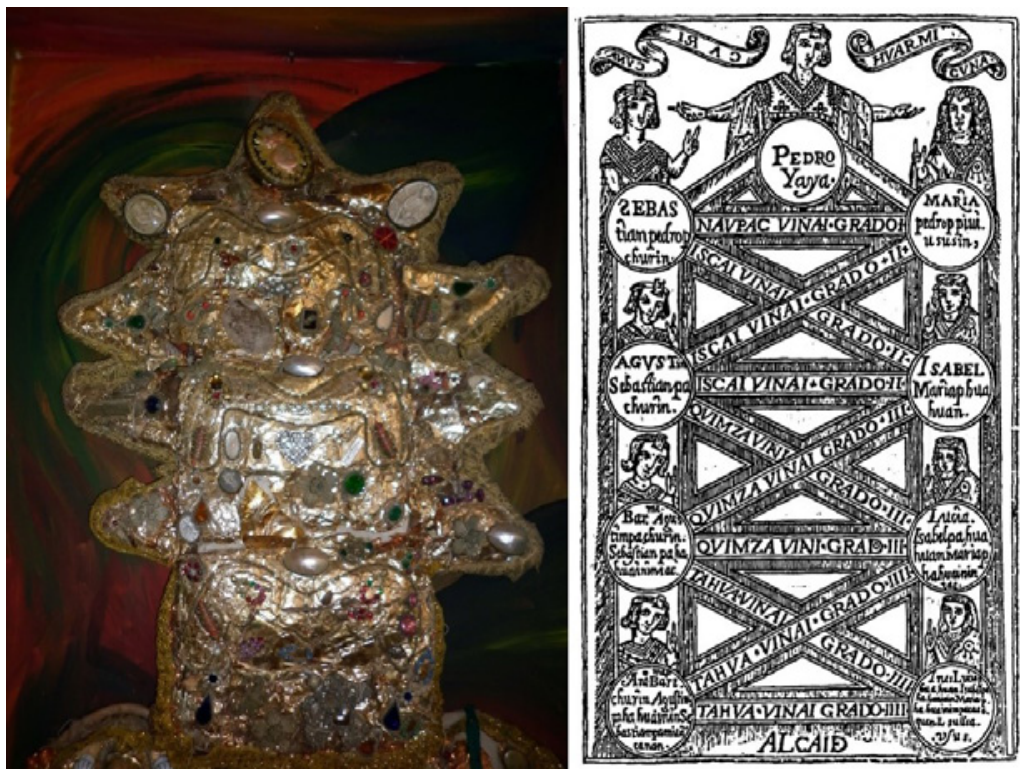

Figura 7. Tocado antiguo (siglo xIx) de un danzante de Pujilí (Colegio Pedro Vicente León, Latacunga). Diagrama genealógico de Juan Pérez Bocanegra.

El esfuerzo por exterminar cualquier síntoma de idolatría a la huaca del ancestro progenitor del ayllu de los ingas e indios chinchaysuyo no terminó en 1743. Otra práctica de sincretismo religioso profundo, y mucho más cercana al tiempo presente, son las piedras hermanas del pueblo de San Juan, por donde pasa un riachuelo afluente del río de Patoa (Figura 2). A un costado del riachuelo se pudo identificar un tramo destruido del camino del Inca que conducía a las tierras privadas de Atahuallpa y en la orilla del puente que une a San Juan con Isinchi, yace una piedra que desde tiempos inmemoriales es reverenciada por sus pobladores que de forma frecuente la engalanan con ofrendas de flores, monedas y manteca (sebo de animal), entre otros materiales, y cada vez que pasan cerca de ella se persignan con el gesto ritual católico para pedir favores al monolito, ya que según sus creencias en la superficie de la piedra están marcadas las huellas de las pisadas del Divino Niño de Isinchi. También los testimonios actuales señalan que, hasta mediados del siglo pasado, eran dos piedras hermanas las que estaban en este sitio, pero el párroco del pueblo se dio cuenta del sentido hereje que producían las piedras y decidió separarlas, llevando una de ellas a la iglesia de San Juan que dista a pocos metros del arroyuelo; la piedra aislada de su entorno primitivo fue colocada en una tarima que se construyó a la entrada de la iglesia, posteriormente en la piedra se pintó 
la imagen de la Virgen y la nueva escultura consagrada a la madre del Dios de los cristianos fue depositada en la parte central del altar mayor. ${ }^{70}$

La piedra o piedras hermanas de San Juan constituyen otro elemento conectado con el concepto del "doble del hermano" y bien podrían evocar a la huanca de Atahuallpa, el héroe fundador del Pujilí de los ingas. Pierre Duviols (1977) en su excelente artículo sobre la litomorfosis del ancestro, propone que el huauqui o efigie del progenitor del ayllu contenía el "alma" de su "alma misma", por eso también era llamado camaquen y, conjuntamente, con la huanca - una especie de menhir plantado en medio del campo o a la entrada del pueblo o llajta - ${ }^{71}$ eran "dobles" del hombre al que estaban atados, objetos sagrados que podían recibir y conservar una parte fluida vital de este hombre, así como otros fluidos exteriores. De hecho, la huanca era la imagen tangible y permanente del fundador épico, la propietaria de la agricultura y garante de la paz urbana. Cada huanca era objeto de un culto, recibía ofrendas de chicha, coca, sebo de llama (manteca) y sacrificios en el curso del calendario tradicional y de ritos agrarios. A cada huanca correspondía un mallqui o el cadáver del progenitor del linaje, ambos tenían un vínculo permanente, pero mientras la huanca se levantaba en el nuevo sitio colonizado por el antepasado, el mallqui o cadáver de este antepasado era depositado lejos del sitio, en una matriz ctónica llamada machay, que equivalía a la pacarina o el lugar mítico de dónde provenía el ancestro fundador del linaje.

Si bien el caso estudiado por Duviols ocurrió en la provincia de Jauja del Perú en 1582, en el Pujilí de los ingas confluyen las mismas nociones de origen andino relacionadas con el culto a los ancestros: la huanca de San Juan estaba ubicada a la entrada de las tierras privadas de Atahuallpa, el fundador del ayllu de los ingas e indios chinchaysuyo y su cadáver súbitamente fue depositado por los incas de la resistencia quiteña en una matriz telúrica que correspondería al sitio inexpugnable de las ruinas arqueológicas incas de Malqui-Machay (Figura 3), construidas de forma intencional en un momento de desestructuración de su cosmovisión y como una respuesta a la turbulencia catastrófica que significó la conquista española.

70 En el trabajo de campo de la expedición No. 18, 13-15/08/2012, se recogió el testimonio de doña Marina Cela Córdova de 74 años de edad. Cuando ocurrió la separación de ambas piedras, es decir a mediados del siglo pasado, ella tenía más o menos 6 años. Su testimonio puede verse en el siguiente vínculo de Internet </www.youtube.com/watch?v=173KtXjL378/>. Sobre una versión escrita de la piedra de San Juan, consúltese Ramírez de Veloz (1994:8082).

71 Según Gerald Taylor (2008:15-16), "El llaqta del manuscrito [Huarochiri] [...] no sólo significaba la comunidad y el centro habitado que le correspondía, sino también indicaba al dios tutelar de la comunidad y a las personas que él protegía, los auténticos llaqtayuqkuna [...] Consecuentemente, llaqtacha- evoca el establecimiento de una comunidad en un lugar determinado, pero también la acción de un ser sobrenatural que se establece en alguna parte como huaca protector". 


\section{UNA EVIDENCIA LINGÜÍSTICA SOBRE EL TOPÓNIMO LATACUNGA}

Según Cieza de León (1996a [1553]:135-137; 1996b [1553]:164), Latacunga fue una provincia inca conquistada por Huayna Cápac Ynga. Tenía una importante jerarquía política y militar, ya que estaba bajo el mando de un mayordomo mayor encargado de la recolección de tributos de la comarca, así como del control de una gran cantidad de mitimaes trasplantados. El cronista quedó, además, deslumbrado por los edificios que vio; a su criterio éstos excedían en perfección a los del Cusco, y también le causó admiración la vestimenta lujosa de sus habitantes. Es probable que las construcciones que observó Cieza de León correspondan al complejo arqueológico inca de San Agustín del Callo ubicado en Mulaló (Figura 2), a pocos kilómetros del volcán Cotopaxi, que constituye, sin lugar a dudas, una las mejores estructuras arquitectónicas de estilo inca imperial en el Ecuador aborigen, conjuntamente con Ingapirca en Cañar y Carangue en Imbabura.

De dónde provenían los mitimaes trasplantados a Latacunga es una pregunta compleja. Por ahora voy a debatir sobre ciertos indicios lingüísticos que permiten identificar por lo menos a un grupo de mitimaes.

Latacunga es un topónimo quechua impuesto por los incas, pero deformado en la literatura colonial y en los documentos de archivo, ya que aparece escrito con variantes como Atacunga, Taconga o Tacunga ${ }^{72}$ o Lactacungas o Llatancunga o Llata-cunga.

Miguel Cabello Balboa (1945 [1586]:346), proporciona una pista temprana en 1586, y menciona a "Lactaccungas". Casi dos siglos más tarde, Giandomenico Coleti (1771:150-151) asentó que el nombre antiguo era un vocablo compuesto por Llatan-cunga, o Llata-cunga. A finales del siglo XIX, Federico González Suárez (1969 [1892]:206), sin citar fuente alguna, escribió que Huayna Cápac Ynga les dijo a los mitimaes que trasplantó a Latacunga "Llactata Cunani", cuya traducción del quichua al castellano — según el presbítero- sería "Os encomiendo, os encargo este hogar, es decir, este territorio", lectura que tuvo eco en la historia local de Latacunga.

En mi opinión el nombre original de Latacunga fue Llajta Congas, por las razones siguientes: Congas es un topónimo que existe como pueblo en la región de Cajatambo en el Chinchaysuyo; Cajatambo fue conquistada en la época de Pachacuti Ynga Yupangui y fue en este distrito que se produjo en el siglo XVII el proceso más agresivo contra la extirpación de la idolatría registrado en los Andes. En la investigación que he realizado, se identificó en la cima de la loma de Cuturiví — tierras privadas de Atahuallpa-

72 Manuel Villavicencio $(1858: 227-228,309)$ utiliza la palabra Tacunga para referirse al cantón y la ciudad. 
una construcción inca denominada por sus actuales moradores como Pucara $^{73}$ Cunga, así como el camino del Inca, bastante bien conservado, que conduce a la fortaleza. ${ }^{74}$ La voz conga o cunga — en singular — también se designa como antropónimo compuesto de indios sueltos y caciques que vivían en el barrio de San Sebastián de Quito y que consta en un padrón del año $1580 .^{75}$ De otra parte, Congas —en plural— figura como antropónimo simple de indígenas llajtayos — mencionados así en el documento del año 1873 - de la parroquia de San Felipe de Latacunga que linda con Pujilí. ${ }^{76}$ También en el juicio de tierras que interpuso Sebastián Malqui contra doña Mencia Inga, se nombra como topónimo a Cungomarca ${ }^{77}$ ubicado en Isinchi, donde habrían estado las "tierras del Sol" que fueron usurpadas - como se recordará - por las familias Loma Portocarrero y Sánchez de Orellana. ${ }^{78}$ Finalmente, en la carta geográfica de Manuel Villavicencio, se asienta como topónimo a Boca Congana, ubicado al sur de Picho que corresponde al sitio arqueológico de Machay y que en algunos documentos aparece nombrado así.

Desde la lingüística, la quechuóloga ecuatoriana Ileana Almeida interpreta Llakta Cunga como una ciudad enclave, en razón de que llakta significa ciudad y cunga, enclave. Los enclaves a su vez podían ser un $\operatorname{tambo}{ }^{79}$ como, por

73 Sobre el vocablo quechua pucara, Cieza de León (1996b [1553]:71), opinó lo siguiente: “[...] los naturales destas provinçias no tenían los pueblos juntos como agora los tienen, sino fortalezas con sus fuertes, que llamavan 'pucaraes', de donde salían a se dar los unos a los otros guerra; y así, siempre andavan recatados y bivían con grandísimo trabajo y desa[so] siego".

74 Trabajo de campo, expedición No. 31, 21-22/11/2013. Tanto Pucara Cunga como el camino del Inca fueron inscritos por la suscrita como bienes patrimoniales ante el Instituto de Patrimonio Cultural de Ecuador, institución que desconocía por completo estos vestigios arqueológicos, a fin de que se les incorpore en el inventario nacional de bienes culturales del país; referencia trabajo de campo, expedición No. 39, 5-6/3/2015.

75 Archivo Iglesia y Convento de San Francisco, Quito: "Padrón de los yndios parroquianos desta yglesia de San Sebastián, assi anaconas como tributarios y los demás que rresiden en esta parroquia", Quito, Libra 1 MFN 9264. En el padrón se enumera a Diego Guano Conga, viudo, indio mindala de Joan de la Vega y a Juan Guano Conga, como principal de los indios sigchos de Joan de la Puente; a Lorenzo Cayza Qunga, como anacona de la loma de Santo Domingo; a Francisco Cayza Qunga y Alonso Maza Conga del ayllu de Pedro Caxas. También constan don Sancho Latacunga y don Pedro Toqunga, como caciques residentes que tenían sus casas en Machángara, el límite de la mencionada parroquia, folios 57, 61, 64v, 65 y $65 \mathrm{v}$.

76 Archivo Gobernación, Cotopaxi, "Reforma del Catastro de Contribuyentes de Latacunga", Pujilí, 03/12/1867, Casilla No. 83, Libra 1 MFN 9233.

77 Según Garcilaso de la Vega (1943a [1609]:283), marca quiere decir fortaleza.

78 Libra 1 MFN 2056

79 Según Gutiérrez de Santa Clara (1963 [c. 1600]:250-251), los tambos eran aposentos o palacios en donde se albergaban los ingas y toda su corte cuando viajaban y podían servir, además, como depósitos para los bastimentos del ejército. 
ejemplo, Tambo Cunga ${ }^{80}$ o una mina, como Qhoya Cunga, actualmente Minas Cunga, o Pucara Cunga en Cuturiví. La autora concuerda con César Itier, que interpreta a conga o cunga como cuello, pero cuando está junto a un sustantivo que significa lugar como llakta, tambo, pukara, etc., no expresa cuello sino que tiene un sentido de posposición y designa una parte de un sitio. Para Rodolfo Cerrón-Palomino — glosado por Almeida — cunga se traduce como aglomerado, reunión, muchedumbre o población. ${ }^{81}$

Gerald Taylor (2000:13, no. 68), discute que "Llacta representa al mismo tiempo la comunidad, el lugar donde reside y el 'dios protector' local de la misma manera que un nombre único designa los tres elementos: los pachacámac, el territorio de los pachacámac y el dios Pachacámac".

Con base en los argumentos lingüísticos y la evidencia etnohistórica y arqueológica, se podría esbozar la siguiente hipótesis:

Llajta Conga o Llajta Cunga fue un conglomerado nuevo fundado por Huayna Cápac Ynga, que trasplantó a los mitimaes de Congas de Cajatambo al sitio donde actualmente está emplazada la ciudad, con lo cual se produjo la colonización de un lugar nuevo. Con la conquista española la ciudad y el corregimiento tomaron el mismo nombre, acaso por ser la zona de mayor densidad poblacional del sector, y el vocablo fue objeto de alteración. Sin embargo, quedaron indicios lingüísticos de la voz original quechua, eso explica la recurrencia del antropónimo Conga o Congas y del topónimo cunga con sentido de posposición. ${ }^{82}$ La migración de los mitimaes de Cajatambo apuntaló, a su vez, la implantación de la lengua vehicular de los incas, de tal manera que el quechua — quichua en Ecuador - que se divulgó en Llajta Conga o Llajta Cunga fue el dialecto del Chinchaysuyo del Perú Central; eso esclarece por qué, en localidades tan remotas como Chugchilán de Sigchos, subsistan topónimos desde el siglo XvI hasta el presente sin alteraciones y que están asociados al culto de los ancestros: me refiero a las voces malqui o el cuerpo del progenitor del ayllu y machay, la morada final o de descanso de los restos mortales del ancestro épico, ${ }^{83}$ locuciones que también se registraron

80 Para María Rostworowski de Diez Canseco (2002:32), Tambo Cunga era uno de los principales asientos de los ayarmacas —en Sarmiento de Gamboa (1942 [1572]:77) consta como Tambocunca - y traduce literalmente ambas voces como "posada de la garganta", sin contemplar el sentido de la posposición que sugieren Ileana Almeida y César Itier.

81 Reconozco a Ileana Almeida por sus valiosos aportes en esta discusión. La información fue proporcionada mediante correo electrónico de fecha 2/9/2015.

82 La posposición sigue al sintagma nominal o a la palabra modificada, regido por ella.

83 En este punto, agradezco a César Itier que me hizo notar que las voces malqui y machay no fueron utilizadas para referirse al cuerpo y a la morada final de los gobernantes incas o capac cuna. Su crítica constructiva me obligó a incursionar en la alternativa lingüística para dar una respuesta etnohistórica sobre la presencia de ambos topónimos en las ruinas arqueológicas incas que descubrí. 
en el proceso de extirpación de idolatrías de Cajatambo, en donde cientos de malquis fueron confiscados de sus machayes (Duviols 2003). ${ }^{84}$

La hipótesis se consolida con un dato etnográfico sorprendente. Curiosamente, en la actualidad, la fiesta patronal —una suerte de celebración mayor que incorpora actos religiosos católicos con prácticas paganasmás importante del distrito de Ocros, al que pertenece el pueblo Congas de Cajatambo, es en honor al inca Atahuallpa, Rumiñahui y las Pallas. ${ }^{85}$ No conozco ninguna otra fiesta patronal en el Perú o en el Ecuador en la que los tres protagonistas confluyan y sean objeto de una celebración con semejante parafernalia, con la circunstancia de que, en la historia oficial del Perú, Atahuallpa y Rumiñahui son personajes polémicos.

Si fueron los mitimaes Congas de Cajatambo los indios chinchaysuyo sujetos al ayllu de los ingas, es otra incógnita enredada, ya que el término Chinchaysuyo como uno de los cuadrantes del imperio inca es un concepto abarcativo del suyo o suyu ${ }^{86}$ o distrito de mayor extensión superficial, que bien podría contener al Cuntisuyo, al Antisuyo y a una parte del Collasuyo, por lo que resulta complicado especificar la procedencia del grupo étnico, aunque también podría ser un conjunto humano diverso. ${ }^{87}$

Este dilema sirve como engarce para discutir acerca de un tema poco estudiado por la historiografía: se trata del elemento castrense integrado por la guardia pretoriana que resguardaba a Atahuallpa, cuando ocurrió su captura en Cajamarca el 16 de noviembre de 1532.

El franciscano criollo fray Buenaventura de Salinas y Córdova, en sus memoriales publicados en 1631, dejó escrita una de las mejores relaciones sobre el ejército que acompañaba a Atahuallpa cuando se dirigía hacia el Cusco para legitimar su estatus como el nuevo y el último cápac del imperio inca.

84 Según la relación sobre la extirpación de la idolatría hecha por el Príncipe de Esquilache (1969 [1621]:90), en este proceso intervinieron 1.618 maestros dogmatizadores que absolvieron a 20.893 brujos maléficos y confiscaron 1.779 ídolos principales, 7.288 dioses penates y 1.365 cuerpos que adoraban, todos juntos hacen 32.943. Por su parte, el padre Pablo José Arriaga (1968 [1621]:200-203) en las visitas contra la idolatría realizadas en 1617 y 1618, registró a 5.694 personas que confesaron sobre sus creencias paganas e identificó 3 guacas principales, 3.418 conopas (dioses lares y penates), 45 mamazaras, 189 huancas y 617 malquies. Para Antonio de la Calancha (2010 [1639]:555-556) la mamazara equivalía a Ceres, que en la mitología romana era la diosa de la agricultura.

85 Sobre la fiesta patronal en Ocros, véase el siguiente vínculo en Internet

$</$ www.ocrosancashperu.com/untitled3.html/>

86 Según González Holguín (2007 [1608]:220), suyu significa parcialidad. En el caso de los cuatro suyus del imperio se trata de extensiones de superficie mayor en las que se incorporaron varios pueblos conquistados, como bien lo percibió Polo de Ondegardo (1917b [1560-72]:51-53).

87 Desde la tradición filológica andina, Taylor (2000:2 no. 7) también encontró dificultad en definir el término "chinchaysuyo"; no obstante, acepta que los elemento léxicos forman parte del Quechua I de los dialectos del Perú central. 
Atagualpa, que traia la mas escogida gente de su Reyno, y de los mejores soldados, que auian sido de su padre, quiso, que fuesse el Capitan General de su exercito, su misma persona Real, poniendose en la borla por insignia de coraje, en lugar de la pluma, que solia traer, vna flecha de oro, que remataua en vna cabeça de culebra con esmaltes rojos, y verdes: y sin salir de sus andas mandó ordenar su campo en la manera siguiente: Puso a los Hanancuzcos, y Huranuzcos, con los principales señores de su casa, y sangre Real cerca de su persona, para que lo assistiessen [...] Mandó al Capitan Rumiñaui, que con cinco mil guerreros Chinchaysuyos, Chachapoyas, Cañares, Quitos, Pastos, Cayambis, Paltas y Caxamalcas estuuiesse de sobre saliente aun [sic] lado del exercito, por la parte, que auia entrado el esquadron de Piçarro, para que no pudiesse huyr; y que acudiesse, si fuera conueniente, cortando por el costado el Real de los Españoles [...] Puso en el cuerno derecho de toda la esquadra a los Midmaes mas velicosos [...] Nombró assi mismo muchos Capitanes de diferentes Prouincias [...] todos exercitados en las guerras de su Padre Guayna Capac (Salinas y Córdova 1957 [1630]:68-69).

¿Qué pasó con estos cinco mil indios guerreros chinchaysuyo, cañarís, pastos, entre otros, así como con los mitimaes más belicosos y los capitanes que se habían ejercitado en las guerras con Huayna Cápac Ynga? ¿Cuál fue el destino final de los señores de sangre real que viajaban con Atahuallpa? Son interrogantes que conducen a una sola comarca: el Pujilí de los ingas.

Toda vez que los conquistadores españoles aniquilaron a las cabecillas de la resistencia inca en Quito, quedó un grupo humano acéfalo y desconcertado. De los hijos de Atahuallpa y sus madres que fueron secuestrados por Diego de Almagro y Sebastián de Benalcázar en los Yumbos, se tiene certeza que cuatro fueron llevados al Cusco y tres quedaron en Quito, a cargo del franciscano fray Jodoco Rique. Posteriormente, estos últimos vástagos y sus familias se establecieron en la parroquia de indios de San Sebastián de Quito. El grupo de la nobleza incaica que no encajó en la capital de la Audiencia, me refiero a los ingas de Conchacapac, habría optado por refugiarse en Pujilí que, en medio de la anarquía, era el único sitio que ofrecía garantías para su sobrevivencia. Y no sería inverosímil que parte de la escolta personal de Atahuallpa y del ejército profesional que se disgregó con la captura y muerte de Rumiñahui y Zopozo Pangue buscara asilo en el mismo pueblo; para algunos de ellos, retornar a sus llajtas de origen en esas condiciones no tenía sentido. ${ }^{88}$

Según la historiografía, los cañarís se identificaron con la causa cusqueña cuando el cisma por la sucesión luego de la muerte de Huayna Cápac Ynga, de hecho, ellos fueron severamente castigados por las tropas de Atahuallpa (Betanzos, 1987:223), y, en la conquista española, se convirtieron en los mejores aliados de los nuevos invasores. Pero, como se ha visto, hubo un grupo de cañarís enfilados en el ejército imperial, posiblemente fue esta tropa la que 
se recogió en Aguallaca, lo cual no sorprende puesto que también la guardia personal de Huayna Cápac Ynga estuvo conformada por indios cañarís, quienes tenían fama por su habilidad castrense y lealtad incondicional al gobernante inca, tal era la confianza que había en ellos, que fueron reservados del tributo y otras cosas, como bien lo anota Murúa [Morúa] (1946 [c. 1590]:204-205).

En cuanto a los indios chinchaysuyo del ayllu de los ingas, es dable que hayan sido indios guerreros y no simples llajtayos, al ser parte de la milicia calificada bien podrían estar identificados con aquellos soldados que acompañaban al señor de Chincha, gobernante étnico que apoyó el ascenso de Atahuallpa como el nuevo cápac del imperio y que estuvo junto a él cuando fue capturado. Ambos iban cargados en andas y fueron sacrificados por los conquistadores españoles (Pizarro 1978 [1571]:37); en la misma línea estarían los indios pastos, no así los indios collasuyo y chan sobre los cuales no tengo una respuesta satisfactoria, pero se podría elucubrar de que fueron indios trasplantados por Huayna Cápac Ynga cuando conquistó Llajta Cunga o bien parte de la escuadra de los "Midmaes mas velicosos" que durante el proceso de la conquista española eligieron como capitán general a Rumiñahui. ${ }^{89}$ Por último, los indios chugchilán estarían asociados con su llajta de origen, donde están ubicadas las ruinas arqueológicas incas de Malqui-Machay.

\section{ConClusión HipotéticA}

El Pujilí de los ingas desenmascara las pesquisas del virrey Francisco de Toledo que, en 1571, mandó a interpelar a más de cien indios del Cusco y sus alrededores para constatar las sospechas sobre las prácticas paganas de que eran objeto los gobernantes ingas difuntos, para la Corona española y la Iglesia católica, era imprescindible comprobar si estos cuerpos secos:

[...] tenían servicio señalado de indios, chacaras y ganado para su servicio y comida de los indios difuntos donde quiera que estaban enterrados, como si estuvieran vivos $[\ldots]$ se enterraban en partes muy secretas y escondidas con los dichos tesoros y riquezas que llevaban consigo, porque no se supiese de ellas (Toledo 1940 [1570-72]:123).

En este artículo se han presentado argumentos sustentados en fuentes de archivo y evidencias arqueológicas y etnográficas que demuestran que en Pujilí se asentó el único ayllu de la nobleza incaica quiteña que sobrevivió a la conquista española. El Pujilí de los ingas fue un grupo corporativo, culturalmente integrado por la descendencia agnaticia de Atahuallpa, encargado de preservar su memoria y de cuidar los símbolos que cohesionaban

89 Una interesante lectura sobre la integración política del señorío de Chincha al imperio Inca, puede consultarse en Morris y Santillana 2007. 
a ese grupo específico, pero también a otros ayllus de distintas nacionalidades. Sería por estas razones que el bulto curado o los restos mortales del fundador épico del ayllu fueron llevados a la pacarina de Malqui-Machay, en tanto que su huauqui sería venerado en las "tierras del Sol" ubicadas en Isinchi y bajo la protección de la huanca de San Juan colocada en la entrada a las tierras privadas del monarca en Cuturiví. El malqui y el huauqui habrían tenido una conexión indisoluble que fluía por medio de una línea imaginaria o ceque que pasaba por la huaca laguna volcán Quilotoa, anclando al cuerpo con su efigie como si fueran una misma esencia y uniendo las tierras privadas del inca y las tierras del sol, con las tierras de comunidad y el mosaico étnico del Pujilí de los ingas (Figuras 2 y 3 ).

El mosaico étnico del Pujilí de los ingas fue una consecuencia de la conquista española y resultado del ambiente de caos gestado después de la muerte de Atahuallpa. Esta circunstancia bruscamente originó una ruptura en la tradición relacionada con los ayllus que cada inca reinante habría fundado en el Cusco, en este sentido el ayllu de la nobleza incaica del Pujilí de los ingas es sui generis y no encaja en la tipología de la historiografía del Perú incaico, ${ }^{90}$ ya que el sitio escogido no fue conquistado por Atahuallpa, sino por su padre Huayna Cápac Ynga. En otras palabras, el progenitor del ayllu no habría colonizado sus propias tierras, pero esto no fue un requisito sine qua non para que el cuerpo seco y su doble fundara[n] su linaje real y que la familia communi iure - "los hijos de los ingas"- preservara las prácticas relacionadas con el culto al pater familias - padre fundador-, expresiones culturales que se fueron adaptando y transformando de acuerdo a los cambios propiciados por la conquista española y el nuevo orden colonial, la república y el presente, de tal forma que es difícil establecer los límites de su autenticidad. Lo importante en este punto es que siguen vigentes y ahora podemos conocer un poco más sobre su creación original.

\section{Bibliografía}

Albornoz, Cristóbal de [c. 1570-1575], "La instrucción para descubrir todas las guacas del Pirú y sus camayos y haziendas", en Pierre Duviols (ed.), Extrait du Journal de la Société des Américanistes, Paris, Musée de l'Homme tome LVI-1:7-40, 1967.

Almeida Reyes, Eduardo; Hampe Martínez, Teodoro, "Patrones funcionales de la arquitectura ceremonial incaica provincia de Cotopaxi", 2013. 
Amado González, Donato, "Sistema de tenencia de tierras de ayllus y panacas incas en el valle del Cusco, siglos Xvi-XviI", en Monica Barnes y otros (ed.): Tribus. Sonderband / Special Edition. Perspectives on the Inca. International Symposium from March 3rd to March 5th, 2014, Germany: Linden-Museum Stuttgart/Universität Bonn/Abteilung für Altamerikanistik: 218-233, 2015.

Archivo Municipal de Quito, Libro de Proveimientos de tierras, cuadras, solares, aguas, etc., por los Cabildos de la Ciudad de Quito, 1583-1594 (Jorge A. Garcés G., ed.), Quito, Municipio de Quito, 1941.

Arriaga, Pablo José [1621], "Extirpación de la idolatría del Perú", en Francisco Esteve Barba (ed.), Crónicas peruanas de interés indígena, Madrid, Biblioteca de Autores Españoles, 209:191-277, 1968.

Assadourian, Carlos Sempat, "Los derechos a las tierras del Ynga y del Sol durante la formación del sistema colonial”, en Segundo Moreno Yánez y Frank Salomon (eds.), Reproducción y transformación de las sociedades andinas siglos $X V I-X X$, Quito, Abya- Yala/Movimientos Laicos para América Latina, núm. 1:215-284, 1986.

Betanzos, Juan de [1551-1557], Suma y narración de los incas, (María del Carmen Martín Rubio, ed.), Madrid, Ediciones Atlas, 1987.

Bonaldi, Francesca, Entre dos culturas: los pintores andinos de Tigua, Quito, AbyaYala/Universidad Politécnica Salesiana, 2010.

Bray, Tamara L., "At the End of Empire. Imperial Advances on the Northern Frontier", en Izumi Shimada (ed.), The Inka Empire. A Multidisciplinary Approach, Austin, University of Texas Press, 325-344, 2015.

Büschges, Christian, Familia, honor y poder. La nobleza de la ciudad de Quito en la época colonial tardía (1765-1822), Quito, FONSAL, 2007.

Cabello Balboa, Miguel [1586], Miscelánea Antártica, Quito, Editorial Ecuatoriana, 1945.

Calancha, Antonio de la [1639], Crónica moralizada del Orden de San Agustín en el Perú con sucesos ejemplares en esta monarquía, 2010, </http://www.scribd. $\mathrm{com} /$.../Antonio-de-la-Calancha-Cronica-moralizada-del-Orden-de-SanAgustin-en-el-Peru/>, (18/01/2010).

Carranza, Martín de [1569], "Relación de las provincias de las Esmeraldas que fue a pacificar el capitán Andrés Contero", en Marcos Jiménez de la Espada (ed.), Relaciones Geográficas de Indias-Perú III, Madrid, Biblioteca de Autores Españoles, 185: 87-91, 1965.

Carrera Colin, Juan, “Apuntes para una investigación etnohistórica de los cacicazgos del Corregimiento de Latacunga SS. XVI y XVII”, Revista Cultura, núm. 4-11:129179, Quito, 1981.

Cerrón-Palomino, Rodolfo, "El legado onomástico puquina: a propósito de 'Capac' y 'Yupanqui'”, Revista Estudios Atacameños. Arqueología y Antropología Surandinas, núm. 41, 119-130, Chile, 2011.

Cieza de León, Pedro, [1553], Crónica del Perú. Primera Parte (Franklin Pease G.Y., ed.), Lima, Pontificia Universidad Católica del Perú, 1996a.

[1553] Crónica del Perú. Segunda Parte (Francesca Cantú, ed.). Lima: Pontificia Universidad Católica del Perú, 1996b.

Cobo, Bernabé, [1653], Historia del Nuevo Mundo, tomo II, Madrid, Biblioteca de Autores Españoles, 92, 1964. 
Coleti, Giandomenico, Dizionario Storico-Geografico Dell'America Meridionale. Venecia, Nella Stamperia Coleti, 2, 1771.

Costales, Piedad y Alfredo, Los Señores Naturales de la Tierra, Quito, Xerox Ecuador/ Editorial Gallocapitán, 1982.

Dean, Carolyn, "The After-life of Inka Rulers: Andean Death Before and After Spanish Colonization", en John Beusterien y Constance Cortez (eds.), Death and Afterlife in the Early Modern Hispanic World, Hispanic Issues On line 7. Minnesota, University of Minnesota, 27-54, 2010.

Duviols, Pierre, "Un symbolisme andin du double: La lithomorphose de l'ancêtre", Actes du XLIIe Congrès International des Américanistes, no. 4:359-364, Paris, 1977.

, Cultura andina y represión. Procesos y visitas de idolatrías y hechicerías, Cajatambo, siglo XVII, Cuzco, Centro Bartolomé de las Casas/IFEA, 1986.

"La interpretación del dibujo de Pachacuti Yamqui", Thérèse Bouysse-Cassagne, (ed.), Saberes y memorias en los Andes. In Memoriam Thierry Saignes, Lima, CREDAL-IFEA, 101-114; 125-148, 1997.

—, Procesos y Visitas de Idolatrías. Cajatambo, siglo XVII, Lima, Pontificia Universidad Católica del Perú/IFEA, 2003.

Espinoza Soriano, Waldemar, "La nobleza inca en Quito: el caso de Capac Yupangue y su hijo Mateo Inga Yupangue”, en Manuel Espinosa Apolo (ed.), La ciudad Inca de Quito, Quito, Tramasocial Editorial, 147-159, 2002.

Espinosa Fernández de Córdova, Carlos, El Inca Barroco. Política y estética en la Real Audiencia de Quito, 1630-1680, Quito, FLACSO, 2015.

Esquilache, Príncipe de, [1621], "Relación sobre la extirpación de la idolatría", Cuadernos del Seminario de Historia, núm. 9, 81-92, Lima, 1969.

Estete, Miguel de, [1535], "Noticia del Perú", Biblioteca Peruana, primera serie núm. 1, 345-402, Lima, Editores Técnicos Asociados S.A., 1968.

Estupiñán Viteri, Tamara, "Testamento de don Francisco Atagualpa", Revista Miscelánea Histórica Ecuatoriana, núm. 1, 8-67, Quito, 1988.

, "El uso de papeles fiduciarios en el sistema económico de la Audiencia de Quito. Un estudio de caso: el banquero Cristóbal Martín", Revista Andina, núm. 34, 135-154, Cuzco, 2002.

, Tras las huellas de Rumiñahui... Quito, Municipio del Distrito Metropolitano de Quito, 2011,

,"Los Sigchos, el último refugio de los incas quiteños. Una propuesta preliminar", Bulletin de l'Institut Français d'Études Andines, no. 40/41, 191204, Lima, 2003.

"Malqui-Machay: cronología del descubrimiento, validación científica, empoderamiento social y puesta en valor", Bulletin de l'Institut Français d'Études Andines, no. 40/43, 593-597, Lima, 2012a.

, "Malqui-Machay, la última morada de Atahualpa", Boletín de la Academia Nacional de Historia, núm. 187, 318-358, Quito, 2012 b.

Bases de Datos Históricos INH (7.897 registros), Libra 1 (9.265 registros) y Libra 2 (1.079 registros), 2015.

Fernández de Oviedo, Gonzalo, [1548], Historia general y natural de las Indias. Tercera parte (Juan Pérez de Tudela Bueso, ed.), Madrid, Biblioteca de Autores Españoles 121, 1959. 
Garcilaso de la Vega (El Inca) [1609], Comentarios Reales de los Incas I (Ángel Rosenblat, ed.) Buenos Aires, Emecé Editores, 1943a. , [1609], Comentarios Reales de los Incas II (Ángel Rosenblat, ed.), Buenos Aires, Emecé Editores, 1943b.

Garrett, David T., Shadows of Empire. The Indian Nobility of Cusco, 1750-1825, New York, Cambridge University Press, 2005.

González Holguín, Diego, [1608], Vocabvlario de la Lengva General de todo el Perv llamada Lengua Qquichua o del Inca, </http://www.runasimipi.org $(26 / 08 / 2008) />, 2007$.

González Suárez, Federico [1892], Historia General de la República del Ecuador, tomo I, Quito, Casa de la Cultura Ecuatoriana, 1969.

Gutiérrez de Santa Clara, Pedro, [c. 1600], Quinquenarios o Historia de las Guerras Civiles del Perú (1544-1548) y otros sucesos de las Indias, Madrid, Biblioteca de Autores Españoles, 166, 1963.

Guamán Poma de Ayala, Felipe [1615-1616], El primer nueva corónica y buen gobierno (Rolena Adorno, ed.), 2004.

Danmarks: Departamento de manuscritos y libros raros/Det Kongelige Bibliotek, $</$ http://www.kb.dk/permalink/2006/poma/info/es/>, (19/3/2009).

Hernández Astete, Francisco, Los Incas y el poder de sus ancestros, Perú, Pontificia Universidad Católica del Perú, 2015.

Herzog, Tamar, “¿Letrado o teólogo? Sobre el oficio de la Justicia a principios del siglo XviII", en Johannes-Michael Scholz (ed.), Fallstudien zur spanischen und portugiesischen Justiz, 15.bis.20 Jahrbhundert. Francfort, 697-714, 1994.

, "La empresa administrativa y el capital social: los Sánchez de Orellana (Quito, siglo XVIII)", en Juan Luis Castellano (ed.), Sociedad, Administración y poder en la España del Antiguo Régimen. Hacia una nueva historia institucional, Universidad de Granada, Granada, 381-396, 1996.

Isbell, William H., Mummies and mortuary monuments: a postprocessual prehistory of central Andean social organization, Austin, University of Texas Press, 1997.

Itier, César, "Las fuentes quechuas coloniales y la etnohistoria: el ejemplo de la Relación de Pachacuti", en Thérèse Bouysse-Cassagne, (ed.), Saberes y memorias en los Andes, In Memoriam Thierry Saignes, Lima, CREDAL-IFEA, 93-100, 1997.

— Les Incas, Paris, Société d'Édition Les Belles Lettres, 2010. , "Las panacas no existieron", en Willem F.H. Adelaar, Pilar Valenzuela Bismarck y Roberto Zariquiey Biondi (eds), Aru, Simi, Taqu, Lengua, Estudios en homenaje a Rodolfo Cerrón-Palomino, Lima, Pontificia Universidad Católica del Perú, 181-193, 2011.

Karolys B., Marco; Ubilla Freire, Juan, Lenguaje popular de la fiesta de la mama negra, Latacunga, Impresora Charito, 2008.

Lavallé, Bernard, Al filo de la navaja: luchas y derivas caciquiles en Latacunga 17301790, Quito, IFEA/Corporación Editora Nacional, 2001.

Loayza, Francisco A., Las costumbres antiguas del Perú y la historia de los Incas (siglo XVI), Por el Padre de la Compañía de Jesús Blas Valera, Lima, Los Pequeños Grandes Libros de Historia Americana, Serie I, núm. 8, 1945.

Loza-Balsa, Gregorio, "Mapa y estudio arqueológico de la provincia de Cotopaxi" (inédito), 1975. 
Miño, Leonardo, El manejo del espacio en el imperio inca, Quito, FLACSO-Ecuador, 1994.

Molina, Cristóbal de (El Cusqueño), [1575], Fábulas y ritos de los Incas (Carlos A. Romero, Raúl Porras Barrenechea y A. Loayza, eds.), Lima, Los Pequeños Grandes Libros de Historia Americana, Serie I, núm. 4, 1-101, 1943.

Morales P., Patricio, Los danzantes del Sol. Mito y realidad del Ecuador Andino, Ecuador. Gobierno Provincial Cotopaxi/Universidad Intercultural de los Pueblos y Nacionalidades Indígenas Amawtay Wasi/Fundación Iberoamericana para el desarrollo Cultural Libertad Andina/CONAIE/PETROECUADOR/ CODEMPE, 2002.

Moreno, Agustín, Fray Jodoco Rique y Fray Pedro Gocial. Apóstoles y Maestros Franciscanos de Quito 1535-1570, Quito, Abya-Yala, 1998.

Moreno Yánez, Segundo E., “Las ‘composiciones de tierras' y el despojo de la propiedad indígena en la región de Latacunga-Ambato (siglo XVII)”, en Udo Oberem y Segundo Moreno Yánez (eds.), Contribución a la etnohistoria ecuatoriana, Quito, Banco Central del Ecuador/Instituto Otavaleño de Antropología/AbyaYala, Colección Pendoneros, 21, 136-154, 1995.

Morris Craig; Santillana, Julián Idilio, "The Inka Transformation of the Chincha Capital", en Richard Burger y otros (eds.), Variations in the Expressions of Inka Power, Washington D.C., Dumbarton Oaks Research Library and Collection/ Trustees for Harvard University, 135-163, 2007.

Mujica Pinilla, Ramón, “El 'Niño Jesús Inca' y los jesuitas en el Cusco virreinal”, en Perú: indígena y virreinal, España, Museau Nacional d'Art de Catalunya/ Ministerio de Cultura, Biblioteca Nacional, 102-106, 2005.

Muratorio, Ricardo, "Los danzantes de Corpus Cristi", en Danzantes de Corpus Christi, Donación de Olga Fisch al Museo del Banco Central del Ecuador, Quito, Banco Central del Ecuador/Impresora Nacional, 1985.

Murúa [Morúa], Martín de [c. 1590], Historia del origen y genealogía real de los Reyes Inças del Perú (manuscrito Loyola) (Constantino Bayle, S.J., ed.), Madrid, Biblioteca Missionalia Hispanica/Instituto Santo Toribio de Mogrovejo, 1946. , [1611-1613], Historia General del Perú (manuscrito Wellington) (Manuel Ballesteros, ed.), Madrid, Historia, 16, 1987. -, [c. 1590], Códice Murúa. Historia y Genealogía Real de los Reyes Incas del Perú, de sus hechos, costumbres, trajes y manera de Gobierno (manuscrito Galvin) (Juan M. Ossio A., estudio), Madrid, Testimonio Compañía Editorial, 2004.

Nair, Stella, At home with the Sapa Inca. Architecture, Space and, Legacy at Chinchero, Texas, University of Texas Press, 2015.

Naranjo, Marcelo, La cultura popular en el Ecuador, tomo II Cotopaxi, Ecuador, Centro Interamericano de Artesanías y Artes Populares, 1996.

Oberem, Udo, Estudios Etnohistóricos del Ecuador. Notas y documentos sobre miembros de la familia del Inca Atahualpa en el siglo XVI, Guayaquil, Casa de la Cultura Ecuatoriana, 1976.

Sancho Hacho, Un Cacique Mayor del siglo XVI, Cayambe: Abya-Yala/CEDECO, 1993. Oliva, Giovanni Anello S.J., [1631], Historia del Reino y provincias del Perú (Carlos M. Gálvez Peña, ed.), Lima, Pontificia Universidad Católica del Perú, 1998. 
Ontaneda, Luciano Santiago, El cacicazgo Panzaleo como parte del área circumquiteña, Quito, Ediciones Banco Central del Ecuador, 2002.

Pereira Valarezo, José, La fiesta popular tradicional en el Ecuador, Quito, Ministerio de Cultura/IPANC, 2002.

Pérez Bocanegra, Juan, Ritval Formvlario, e Instituvion de cvras, para administrar a los natvrales de este Reyno, los santos Sacramentos del Baptismo, Confirmacion, Eucaristia, y Viatico, Penitencia, Extremavncion, y Matrimonio, Con aduertencias muy necessarias, Lima, Impreso por Gerónimo de Contreras, 1631.

Pizarro, Pedro [1571], Relación del Descubrimiento y conquista del Perú (Guillermo Lohmann Villena y Pierre Duviols, eds.), Lima, Pontificia Universidad Católica del Perú, 1978.

Polo de Ondegardo, Juan, [1571], "Relación de los adoratorios de los indios en los cuatro caminos (zeques) que salían del Cuzco", en Horacio H. Urteaga, Informaciones acerca de la religión y gobierno de los incas, segunda parte por el licenciado Polo de Ondegardo. Seguidas del estado y economías de los naturales del Perú que se dicen indios y medios simplísimos de corregir, Lima, Colección de libros y documentos referentes a la Historia del Perú, núm. 4, 3-43, 1917a.

, [1560-72] "Del linage de los Ingas y como conquistaron", en Horacio H. Urteaga, Informaciones acerca de la religión y gobierno de los incas, segunda parte por el licenciado Polo de Ondegardo. Seguidas del estado y economías de los naturales del Perú que se dicen indios y medios simplísimos de corregir, Lima, Colección de libros y documentos referentes a la Historia del Perú, núm. 4, 45-94, $1917 \mathrm{~b}$.

Ramírez De Velóz, Judith, Leyendas y Tradiciones de mi tierra, Pujilí, 1994.

Rostworowski De Diez Canseco, María, "Nuevos Datos sobre Tenencia de Tierras Reales en el Incario", Revista del Museo Nacional, núm. 31, 130-164, Lima, 1962.

- Historia del Tahuantinsuyu, Lima, Instituto de Estudios Peruanos, 2002.

Rueda, Marco Vinicio, La fiesta religiosa campesina, Quito, Universidad Católica del Ecuador, 1982.

Ruiz Navas, José Mario, "Eloy Alfaro y la Diócesis de Portoviejo", Revista Procesos, núm. 23, 135-150, Quito, 2006.

Salinas y Córdova, Buenaventura de, [1630], Memorial de las Historias del Nuevo Mundo Pirú (Luis E. Valcárcel, ed.), Lima, Universidad Nacional Mayor de San Marcos/Colección Clásicos Peruanos, 1957.

Sancho De La Hoz, Pedro [1534], "Relación para su Majestad", Biblioteca Peruana, primera serie núm. 1, 277- 343, Lima, Editores Técnicos Asociados, S.A., 1968.

Santillán, Hernando de [1563], "Relación del origen, descendencia, política y gobierno de los Incas”, en Francisco Esteve Barba (ed.), Crónicas peruanas de interés indigena, Madrid, Biblioteca de Autores Españoles, 209, 97-149, 1968.

Sarmiento de Gamboa, Pedro [1572], Historia de los Incas, Buenos Aires, Emecé Editores, 1942.

Taylor, Gerald, "Camac, Camay y Camasca en el manuscrito quechua de Huarochiri", Travaux de l'Institut Français d'Études Andines, núm. 126, 1-17, Lima, 2000. 
¿Tomás? Ritos y tradiciones de Huarochirí, Lima, Instituto Francés de Estudios Andinos/Instituto de Estudios Peruanos/Universidad Nacional Mayor de San Marcos, 2008.

Toledo, Francisco de [1570-72], "Informaciones que mandó levantar el Virrey Toledo sobre los Incas. Su origen, provisión y sucesión de cacicazgos, ritos, costumbres y descendencia, y sobre el gobierno que tenían los pueblos del Perú antes de ser reducidos y conquistados por ellos", en Roberto Levillier, Don Francisco Toledo supremo organizador del Perú: Su vida, su obra (1515-1582), Buenos Aires, Imprenta Porter hermanos, núm. 2, 1-204, 1940.

Vázquez de Espinosa, Antonio [1629], Compendio y descripción de las Indias Occidentales (Charles Upson Clark, ed.), Washington D.C., Smithsonian Miscellaneous Collections, 1948.

Villavicencio Montúfar, Manuel, Geografía de la República del Ecuador, New York, Imprenta de Robert Craighead, 1858.

Xerez, Francisco de [1534], Verdadera Relación de la Conquista del Perú (Concepción Bravo, ed.). Madrid: Historia 16, 1985.

Yánez del Pozo, José, Yanantín la filosofía dialógica intercultural del Manuscrito de Huarochiri, Quito, Abya-Yala, 2002.

Zuidema, Tom R., Reyes y guerreros (Manuel Burga, comp.), Lima, Grandes Estudios Andinos/FOMCIENCIAS/CONCYTEC/SHELL/IFEA/Talleres Gráficos P.L., 1989.

, El sistema de ceques del Cuzco: la organización de la capital de los Incas: con un ensayo preliminar, Lima, Fondo Editorial de la Pontificia Universidad Católica del Perú, 1995.

"La política matrimonial incaica según Juan de Betanzos: un ejemplo implicando a los reyes Inca Roca y Yahuar Huáca”, en Rafael Varón Gabai (ed.), Arqueología, Antropología e Historia de los Andes. Homenaje a María Rostworowski, Lima, Instituto de Estudios Peruanos/Banco Central de Reserva del Perú, 289-300, 1997a.

, "Pachacuti Yamqui Andino. Respuesta de Tom Zuidema a Pierre Duviols" en Thérèse Bouysse-Cassagne, (ed.), Saberes y memorias en los Andes. In Memoriam Thierry Saignes, Lima, CREDAL-IFEA, 115-123; 149-154, $1997 \mathrm{~b}$. 